MICE Note 291

\title{
Results from the Cooler and Lead Tests
}

\author{
Michael A. Green \\ Lawrence Berkeley National Laboratory \\ Berkeley CA 94720, USA
}

20 June 2010

\begin{abstract}
The report presents the results of testing MICE spectrometer magnet current leads on a test apparatus that combines both the copper leads and the high temperature superconducting (HTS) leads with a single Cryomech PT415 cooler and liquid helium tank. The current is carried through the copper leads from $300 \mathrm{~K}$ to the top of the HTS leads. The current is then carried through the HTS leads to a feed-through from the vacuum space to the inside of a liquid helium tank. The experiment allows one to measure the performance of both cooler stages along with the performance of the leads. While the leads were powered we measured the voltage drops through the copper leads, through the HTS leads, through spliced to the feed-through, through the feed-through and through the low-temperature superconducting loop that connects one lead to the other.

Measurements were made using the leads that were used in spectrometer magnet 1A and spectrometer magnet $2 \mathrm{~A}$. These are the same leads that were used for Superbend and Venus magnets at LBNL. The IL/A for these leads was $5.2 \times 10^{6} \mathrm{~A} \mathrm{~m}^{-1}$. The leads turned out to be too long. The same measurements were made using the leads that were installed in magnet 2B. The magnet $2 \mathrm{~B}$ leads had an IL/A of $3.3 \times 10^{6} \mathrm{~A} \mathrm{~m}^{-1}$. This report discusses the cooler performance and the measured electrical performance of the lead circuit that contains the copper leads and the superconducting leads. All of the HTS leads that were installed in magnet $2 \mathrm{~B}$ were current tested using this apparatus.
\end{abstract}

\section{Table of Contents}

$\begin{array}{lc}\text { Abstract } & 1 . \\ \text { Table of Contents } & 1 . \\ \text { Introduction } & 2 . \\ \text { Previous Drop-in Cooler Experiments } & 3 . \\ \text { Optimization of the Copper Leads } & 6 . \\ \text { The Lead Test Experimental Apparatus } & 10 . \\ \text { Temperature Calibration of the 4.2 K Diode Sensors } & 16 . \\ \text { The Results of Thermal Tests with the Copper Leads Installed } & 18 . \\ \text { The Results of Voltage Drop Measurements } & 26 . \\ \text { Some Concluding Comments, "What was learned from these tests?" } & 31 . \\ \text { Acknowledgments } & 33 . \\ \text { References } & 33 . \\ \text { Appendix } & 35 .\end{array}$




\section{Introduction}

The cooling channel magnets for MICE [1] are all superconducting solenoids that are designed to be kept cold using small 4.2 K coolers [2]. The MICE cooling channel has three types of magnet modules within it. The first of the channel magnets to be installed at MICE will be the spectrometer solenoids [3]. The second magnet type to be installed at MICE is absorber focus coil (AFC) module [4]. The third type of magnet to be installed at MICE will be the RF coupling coil modules [5], [6].

The magnet coolers selected for the MICE magnets are Cryomech PT415 two-stage pulse tube coolers [7] that will provide $1.5 \mathrm{~W}$ of cooling at $4.2 \mathrm{~K}$ while providing $42 \mathrm{~W}$ of cooling at 40 to $42 \mathrm{~K}$ (depending on the amount second-stage refrigeration needed). Pulse tube coolers were selected because the coolers must operate in a magnetic field up $0.3 \mathrm{~T}$ [8] [9]. Along with the coolers, the high temperature superconducting (HTS) leads must also be able to operate in a magnetic field [9], [10]. The stray field from the MICE magnets determines the type of cooler used, the position of the cooler, and the type of HTS leads that are connected to the cooler first stage at the upper end and the magnet cold mass at the lower end [10].

The MICE magnets are cooled using liquid helium in a tank or in tubes that are attached to the outside of the cold mass. The cooling must be provided around the circumference of the solenoid as well as along its length. This ensures that the cold is evenly distributed within the magnet volume [11]. The connection between the cooler second-stage and the cold mass will be made using a natural convection thermal siphon type of circuit that condenses helium gas from the magnet and distributes the liquid helium back to the magnet cold mass [12], [13]. The system should be designed to minimize the temperature drop between the magnet hot spot and the second stage cold heads [14]. This improves the temperature margin of the superconducting magnets.

The first-stage temperature of the cooler is just as important as the second stage temperature. The heat into the cooler first stage comes from a number of sources; conduction through the cold mass support, conduction down the copper leads that carry the current to the top of the HTS leads, conduction down vent and cool down pipes, conduction down the cooler mounting sleeves, conductions down the instrumentation wires and thermal radiation and gas conduction across the multi-layer insulation (MLI). In theory, the dominant heat load to the cooler first stages is heat coming into the top of the HTS leads from the copper current leads that connect the HTS leads to room temperature. The minimum optimum heat leak down the copper leads is about $94 \mathrm{~W}$ per 1000 A lead pair [15] [16].

The temperature drops in the copper plates that connect the tops of the HTS leads to the cooler first stage are very important, if one wants to maintain a large temperature margin for the HTS leads [17]. The temperature drop from the cold mass intercept points on the shield is also. The temperature of the shield and the intercepts directly affects the heat flow into the cold mass and the cooler second-stages.

The MICE spectrometer and coupling magnets use drop-in PT415 coolers. There are three temperature drops that must be considered in a system with drop in coolers. The first $\Delta \mathrm{T}$ is between the copper ring and the cooler first-stage. The second $\Delta \mathrm{T}$ is between the top of the HTS leads and the copper plate next to the leads. The third $\Delta \mathrm{T}$ is along the copper plate to the ring around the cooler first stage. 
This report will discuss a number of issues that must be addressed in an experiment that allows copper and HTS leads to be connected to a tank of liquid helium, which is kept cold using a PT415 cooler that is connected to the liquid helium with a freeconvection thermal siphon loop. First, the drop-in coolers have been tested using three different methods of connecting the cooler second stages to the liquid helium tank. The results of previous drop in coolers tests will be presented. Second, the topic of the optimization of the copper leads will be discussed. The design of the leads is an important factor is the overall heat load that is seen by the cooler first-stages. Third, the lead and cooler experimental apparatus will be discussed in some detail. Fourth, the results of the calibration of the $4 \mathrm{~K}$ temperature sensors will be presented. Fifth, the results of the lead thermal tests will be presented and analyzed. Sixth, the results of the voltage drop measurements across various parts of the lead circuit will be discussed.

\section{Previous Drop-in Cooler Experiments}

A series of drop-in cooler experiments were operated from late 2007 [18] to late 2008 [19]. Three arrangements for connecting the cooler to the helium tank to the magnets were tested. The three cooler connection arrangements are shown in Figure 1.

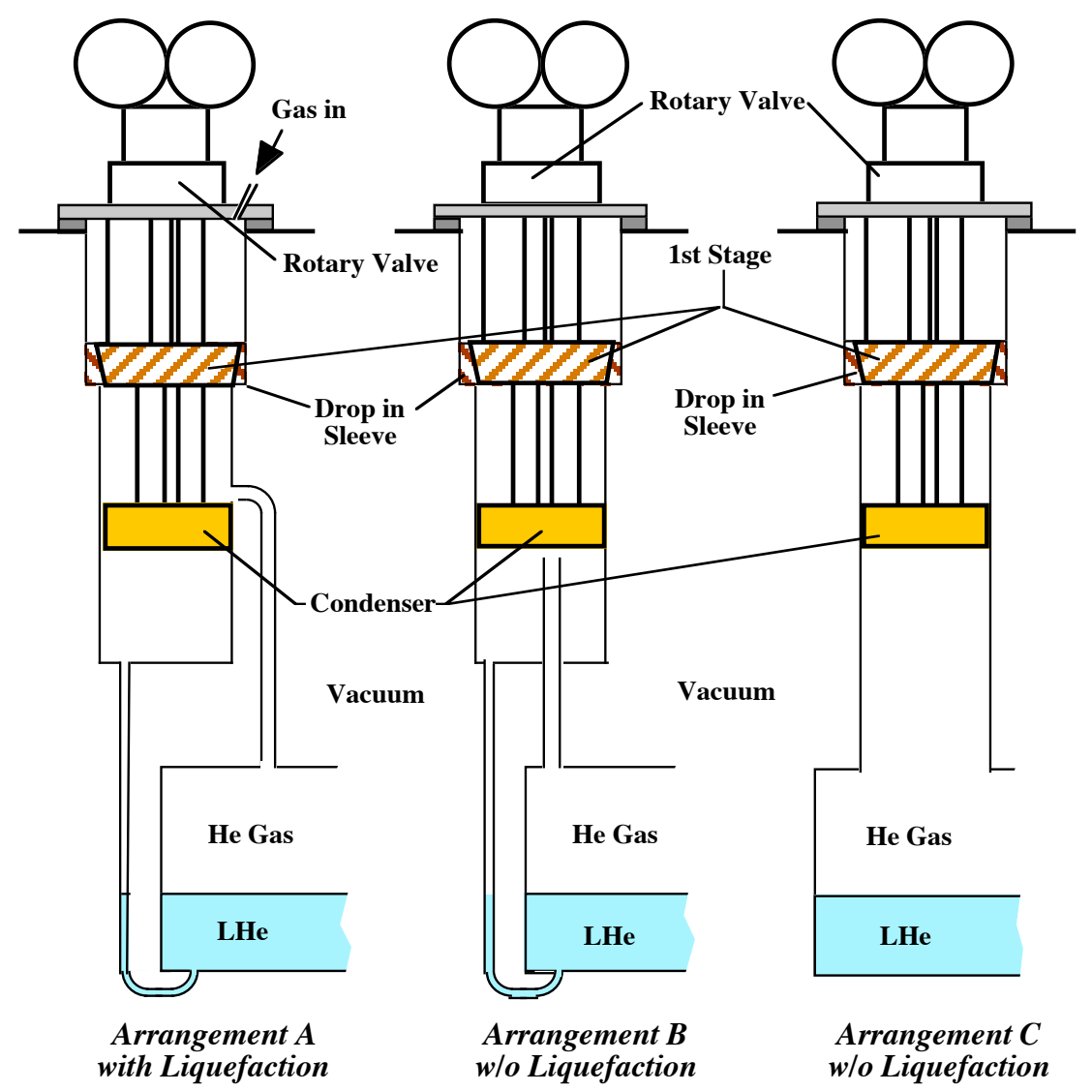

Figure 1. The Arrangements of Coolers and Helium Tank for the three drop-in cooler tests done by LBNL 
Arrangement A in Figure 1 has been discussed in References [12] through [14]. This configuration permits on to feed the condensed liquid to the bottom of the helium tank while feeding the boil-off helium to the space just above the condenser. If warm helium gas is fed into the drop in cooler tube at the top of the cooler, this gas can be precooled using the pulse tube and regenerator tube before it is pre-cooled using the cooler first stage. After further pre-cooling by the cooler first stage, the pulse tube and regenerator tube between the first and second stages can be used for more gas precooling. Arrangement $\mathrm{A}$ is well suited for the pre-cooling of the helium tank and the liquefaction of helium, even without extended heat exchange surfaces on the first stage or the cooler tubes [20], [21]. Using arrangement A, we were able to cool down the experiment and liquefy helium into the tank using the cooler alone. Ideally one wants to use the configuration shown in arrangement A to cool all of the MICE magnets. The spectrometer magnet vendor felt that arrangement A was difficult to assemble on the magnet. As a result, arrangement B was tested for use in the first spectrometer solenoid.

Arrangement B as shown will not liquefy helium. If gas is brought into the cooler sleeve at the room temperature end as shown in arrangement $\mathrm{A}$, helium liquefaction may be possible. This was not tested. The disadvantage is that the return gas from the tank is brought to the bottom of the condenser. When tested in the drop-in cooler experiment, arrangement B appeared to re-condense about as well as arrangement A. In both cases re-condensation was achieved even when $1.3 \mathrm{~W}$ was put into the helium in the tank. The sleeve around the cooler the vent pipes and the instrumentation wires going into the experiment accounted for 0.3 to $0.4 \mathrm{~W}$ of extra heat leak that is seen by the cooler second stage. The tubes and cooler sleeve added an additional 2 to 4 watts to the first stage of the cooler. On the second stage, vent tubes, the sleeve, and the instrumentation wires account for 20 to 25 percent of the cooler second-stage capacity at $4.2 \mathrm{~K}$. The tubes and cooler sleeve reduced the effective capacity of the cooler first-stage by 5 to 10 percent. As a result of the second cooling test using arrangement $\mathrm{B}$, the first spectrometer magnet was connected to its coolers using arrangement B.

Magnet 1 was tested in 2008. We found that the cooler second stage was not connected to the magnet. The tube that connected to the bottom of the tank was plugged with nitrogen ice, which broke the connection between the condenser and the magnet cold mass [22]. Between tests, magnet 1 was allowed to warm up to about $65 \mathrm{~K}$ with the coolers running, as a result, the tubes that connected the gas space to the condenser became clogged with nitrogen ice. (There was lots of nitrogen in the tank.) As a result, the region around the condenser was at temperatures in the range from 3.2 to $3.5 \mathrm{~K}$, which indicates that there was virtually no cooling being transferred from the cooler second-stages to the cold mass. During the magnet cool-down using liquid cryogens, the tank was allowed to collect liquid nitrogen. The tank was not properly pumped and purged. As a result, the connection between the coolers and the cold mass was clogged with nitrogen ice. Ideally, liquid nitrogen should never have been allowed to collect in the tank. The nitrogen flow should have been stopped when the resistance of the superconducting coil went down a factor of six. To prevent the connection from the cooler to the cold mass from being blocked by nitrogen ice, arrangement $\mathrm{C}$ was adopted.

The drop in coolers seemed to work about as well using arrangement $\mathrm{C}$ as with arrangement $\mathrm{B}$. We were able to re-condense with up to $1.25 \mathrm{~W}$ being added to the liquid helium tank. As a result, a modified form of arrangement $\mathrm{C}$ was used for spectrometer magnet 2 . In magnet 2 , the liquid dripped into a manifold, then into the helium tank. 
Before one can understand results of the lead cooler experiment, it is useful to understand the operating characteristics of a PT415 cooler over a range of first-stage and second-stage temperature [23]. Figure 2 shows the operating temperatures for the firststage (the $\mathrm{x}$ axis) and the second stage (the $\mathrm{y}$ axis) for a PT415 cooler over a range of operating refrigeration Q1 on the first-stage from 0 to 84 watts in increments of 21 watts. The range for the second-stage refrigeration Q2 in Figure 2 is from 0 to $3.0 \mathrm{~W}$ in increments of 0.5 watts. When one compares the data in Figure 2 with the data measured for the coolers by Cryomech, the data is quite good. It appears there is a residual heat load into the cooler first-stage of about $1 \mathrm{~W}$. The residual heat load into the cooler second-stage could be about $0.1 \mathrm{~W}$.

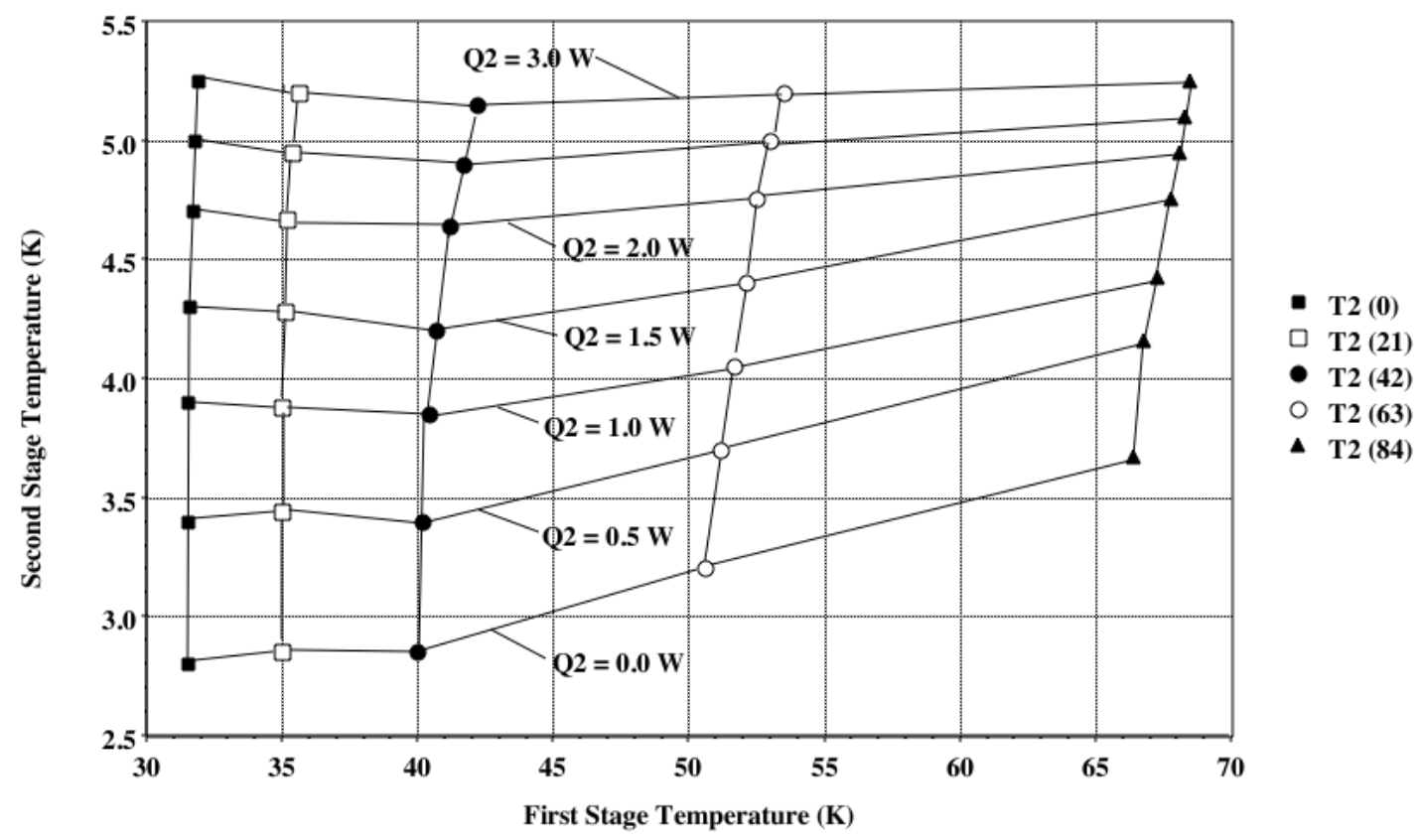

Figure 2. Operating temperature diagram for the first-stage temperature $\mathrm{T} 1$ and the second-stage temperature T2 of a PT415 pulse tube cooler as a function of the first-stage heat load Q1 and the secondstage heat load Q2. (Data taken by Florida State University [23].)

From Figure 2, it is clear that at low values of the stage-1 heat load Q1 $(<42 \mathrm{~W})$, the effect of the stage-2 heat load Q2 on stage-1 is virtually zero. As the heat load into stage1 increases, the effect of the stage- 2 heat load on the first-stage temperature becomes more pronounced. At stage-1 heat loads Q1 above $42 \mathrm{~W}$, the stage-2 temperature T2 goes up for a given stage-2 heat load Q2. The diagram shown in Figure 1 shows the importance of keeping the cooler first stage temperature low (below $45 \mathrm{~K}$ ). It appears that the PT415 cooler performance is optimum for a first-stage heat load of about $42 \mathrm{~W}$. The PT415 cooler operating diagram shown in Figure 2 is expected to apply in the United Kingdom, where the power frequency is $50 \mathrm{~Hz}$ rather than the $60 \mathrm{~Hz}$. This is true provided the cooler hose is charged to the correct pressure for the operating frequency. The reason for this is that the rotating valve frequency of $1.2 \mathrm{~Hz}$ is independent of the AC electric power frequency from the grid. 


\section{Optimization of the Copper Leads}

The copper leads from $300 \mathrm{~K}$ to the top of the HTS leads must be optimized to minimize the heat flow into the cooler first-stage. We found that during the first test of magnet 2 (magnet test 2A), the heat leak from the 275 A copper leads that connect to room temperature appeared to be excessive. The large heat leak from the leads combined with large heat leaks into the shields of magnet 2A led to one of the HTS leads being burned-out during the July 2009 test of the magnet. The fact that the lead optimization appeared to be incorrect led to the lead cooler tests in January and February of 2010.

Powered magnets that are cooled using small coolers have HTS-leads between the cooler first-stage and the cooler second-stage. Between room temperature and the cooler first-stage the leads are conduction-cooled to the cooler first-stage. In general, the conduction-cooled leads are optimized to a current that is near the maximum magnet current. The MICE coupling and focusing magnet leads can be optimized to 80 percent of the current needed for $\mathrm{p}=240 \mathrm{MeV} / \mathrm{c}$ and $\beta=420 \mathrm{~mm}$ in the center of the absorber. The optimum-current is $275 \mathrm{~A}$ for the spectrometer magnet and the two match coil leads. The small leads used for tuning are optimized for a current of $60 \mathrm{~A}$.

A conduction-cooled lead or a gas cooled lead is optimized so that the net heat flow in the top of the lead (at say $293 \mathrm{~K}$ ) is zero. When a conduction-cooled lead is operating at its optimum-current, all of the heat leaving the lead at the bottom is from resistive heating. (The same statement is true for a gas-cooled power lead as well.) An optimumlead has $\mathrm{dT} / \mathrm{dz}=0$ at the room temperature end of the lead $\left(\mathrm{z}=\mathrm{L}_{\mathrm{L}}\right)$, when it is operating at its optimum current $I_{0}$. The heat leak down a lead to the cooler first-stage (without gas cooling) can be calculated using the following expression [15], [24];

$$
Q_{l}=\left[L_{o}\left(T_{R}^{2}-T_{1}^{2}\right)\right]^{0.5} I_{0} \approx 3.6 \frac{k_{B} T_{R}}{e} I_{0}
$$

where $Q_{I}$ is the heat leak down an optimum lead carrying a current $\mathrm{I}_{\mathrm{o}}$ with an upper end temperature $T_{R}\left(T_{R}\right.$ is room temperature.) and a lower end temperature $T_{1}\left(T_{1}\right.$ is the cooler first-stage temperature. $\mathrm{L}_{\mathrm{o}}$ is the Lorenz number; $\mathrm{k}_{\mathrm{B}}$ is Bolzmann's constant; and e is the charge of an electron. (Nominally $\mathrm{L}_{\mathrm{o}}=2.45 \times 10^{-8} \mathrm{~W} \Omega \mathrm{K}^{-2} ; \mathrm{k}_{\mathrm{B}} 1.38 \times 10^{-23} \mathrm{~J} \mathrm{~K}^{-1}$ and the charge of an electron $\mathrm{e}=1.6 \times 10^{-19}$ coulomb.) When the lead operates at its optimum current with $\mathrm{T}_{\mathrm{R}}=293 \mathrm{~K}$ and $\mathrm{T}_{1}=60 \mathrm{~K}, \mathrm{Q} / \mathrm{I}_{\mathrm{o}}=0.045 \mathrm{~W} \mathrm{~A}^{-1}$ per lead.

The other lead design issue is the $\mathrm{I}_{0} \mathrm{~L} / \mathrm{A}$ function that relates the lead design current $I_{o}$ to the lead length $L_{L}$ and cross-section area $A_{c}$. One can estimate the IL/A for a current lead with a design current $\mathrm{I}_{\mathrm{o}}$ (whether it is gas-cooled or not) by using the following approximate expression [16];

$$
\left[\frac{I_{0} L_{L}}{A_{c}}\right]_{\text {opt }}=j_{0} L_{L}=\frac{Q_{1}}{I_{0} \rho_{\text {eff }}}=\frac{1}{\sqrt{L_{O}}} \int_{T_{1}}^{T_{R}} \frac{k(T) d T}{\sqrt{\left(T_{R}^{2}-T^{2}\right)}}
$$

where $L_{L}$ is the lead length; $A_{c}$ is the lead cross-section area; $j_{0}$ is the lead current density; $\rho\left(T_{1}\right)$ is the lead conductor resistivity at the bottom of the lead (at temperature $T_{1}$ ) and $\rho_{\text {eff }}$ is the effective resistivity of the lead. The IL/A given by equation 2 is accurate, but it required numerical integration to solve the equation. It is clear that leads made from high RRR material (a pure metal) have a lower $\rho_{\text {eff }}$, and as a result, leads will be longer. Leads 
that are made from pure metals (such as $R R R=300$ copper) do not operate well when the current is even 20 percent over the design current. Low RRR leads are much shorter, and they can operate off their optimum current without much penalty [15].

An approximate equation commonly used to design gas cooled leads that have their bottom ends at $10 \mathrm{~K}$ or lower is as follows [25];

$$
\left[\frac{I_{0} L_{L}}{A_{c}}\right]_{o p t} \approx 286\left[\rho\left(T_{1}\right)\right]^{-0.5}
$$

Equation 3 has been applied to a conduction cooled lead where $T_{1}$ is the temperature of the top of the HTS lead. Unfortunately equation 3 doesn't appear to work as well as one would want. It appears that the IL/A calculated using this equation is too high.

The calculation of the cross-section comes from the adiabatic burnout equation for a metal lead. The expression that this is derived from is the same expression as is used for the quench hot-spot temperature in a superconducting magnet [26]. The equation for lead burn-out can be stated as follows [26], [27];

$$
F *(T)=\int_{T_{S}}^{T_{F}} \frac{C(T)}{\rho(T)} d T=\int_{0}^{t} j(t)^{2} d t
$$

where $C(T)$ is the specific heat per unit volume as a function of temperature $T ; \rho(T)$ is the electrical resistivity as a function of $\mathrm{T}$; and $\mathrm{j}(\mathrm{t})$ is the current density in the conductor cross-section as a function of time $t$. Note; $j(t)=I(t) / A_{c} . T_{S}$ is the starting temperature at the top of the lead (say $T_{S}=293 \mathrm{~K}$ ) and $T_{F}$ is the maximum allowable temperature of the top of lead ( say $\mathrm{T}_{\mathrm{F}}=400 \mathrm{~K}$ ). It can be argued that the adiabatic equation given above don't really apply, because heat is flowing from both lead ends the copper lead. Leads running at a high current density are shorter than leads running at a lower current density. Experience with gas-cooled leads suggests that the design lead current density $\mathrm{j}_{\mathrm{o}}$ should be set as high as $2 \times 10^{7} \mathrm{~A} \mathrm{~m}^{-2}$ [26], [27]. This current density is 10 to 30 times higher than the current density given by the equation above.

An optimum lead has no net heat flow at the room temperature end [15, 24]. All of the heat that leaves the lead at its low temperature end comes from $i^{2} R$ heating. At currents greater than the lead optimum design current, there will be heat flowing from the lead from the room temperature end. This heat will be carried away by natural convection and radiation. At currents less than the lead optimum design current, there will be heat flowing into the lead from the room temperature end. This can cause condensation or freezing of water on the room temperature of the lead, unless there is an added source of heat. Because the heat is from two separate sources, the heat flow from the low temperature end of the lead at zero current is half of the heat flow from the low temperature end of the lead, when the lead operates at its optimum current. Wilson's study of gas-cooled stated that the cold end heat leak at zero current is from 40 to 70 percent of the cold end heat leak at the optimum current, depending on the RRR of the copper. If IL/A is correct, heat leak at zero current for conduction-cooled leads will be half the heat flow when the lead is operating at its design current (regardless of the metal used to fabricate the lead) [24]. 
The heat flow from the room temperature end $\left(T_{R}=\sim 293 \mathrm{~K}\right)$ to the low temperature end $\left(\mathrm{T}_{1}=\sim 60 \mathrm{~K}\right)$ of a constant cross-section conduction cooled leads can be calculated using the following approximate expression;

$$
Q_{0}=\frac{A_{c}}{L_{L}} \int_{T_{1}}^{T_{R}} k(T) d T
$$

where $Q_{0}$ is the heat flow at the cold end of the single lead; $A_{c}$ is the cross-section area of the lead (Note, $A_{c}=\sim 10^{-7} \mathrm{I}_{\mathrm{o}}$.); $\mathrm{L}_{\mathrm{L}}$ is the length of the lead; and $\mathrm{k}(\mathrm{T})$ the lead material thermal conductivity as a function of temperature $\mathrm{T}$.

Table 1 shows the design parameters for three types conduction cooled leads. One lead is made from $\mathrm{RRR}=5 \mathrm{Cu}$; the second lead is made from $\mathrm{RRR}=30 \mathrm{Cu}$; and the ICST design $(R R R=10 \mathrm{Cu})$. Similar calculations could be made for leads fabricated from other materials.

Table 1. Some Design Parameters for Conduction Cooled Leads Fabricated from RRR = 5 and RRR= 30 Copper Compared with the ICST Lead Design

\begin{tabular}{|c|c|c|c|}
\hline Lead Parameters & RRR $=5 \mathrm{Cu}$ & $\mathbf{R R R}=30 \mathrm{Cu}$ & ICST Design \\
\hline Top End Temperature $(\mathrm{K})$ & & 293 & \\
\hline Bottom End Temperature (K) & & 60 & \\
\hline Powered Lead Heat Leak ( $\left.\mathrm{W} \mathrm{A}^{-1}\right)$ & & 0.045 & \\
\hline Bottom End Resistivity $(\Omega \mathrm{m})$ & $\sim 4.06 \times 10^{-9}$ & $\sim 2.77 \times 10^{-9}$ & $\sim 3.80 \times 10^{-9}$ \\
\hline Lead $\mathrm{I}_{\mathrm{o}} \mathrm{L}_{\mathrm{L}} / \mathrm{A}_{\mathrm{c}}\left(\mathrm{A} \mathrm{m}^{-1}\right)^{*}$ & $4.49 \times 10^{6}$ & $5.43 . \times 10^{6}$ & $3.1 \times 10^{6}$ \\
\hline Lead Current Density $\left(\mathrm{A} \mathrm{m}^{-2}\right)$ & $10^{7}$ & $10^{7}$ & $10^{7}$ \\
\hline Optimum Lead Length (m) & 0.449 & 0.543 & 0.300 \\
\hline $\int \mathrm{k}(\mathrm{T}) \mathrm{dT}$ from 60 to $293 \mathrm{~K}\left(\mathrm{~W} \mathrm{~m}{ }^{-1}\right)$ & $8.7 \times 10^{4}$ & $10.7 \times 10^{4}$ & $9.1 \times 10^{4}$ \\
\hline Un-powered Lead Heat Leak $\left(\mathrm{W} \mathrm{A}^{-1}\right)$ & 0.0193 & 0.0196 & 0.0303 \\
\hline Ratio (Un-powered Q)/(Powered Q) & 0.431 & 0.440 & 0.674 \\
\hline
\end{tabular}

* For the ICST leads Equation 2 was used. For the other two leads, Equation 3 was used

The ratio of un-powered heat leak to the powered heat leak at optimum current in Table 1 for the first two leads is around 44 percent. This suggests that the calculated IL/A using equation 3 may be too large. The ratio shown in the table is nearly the same ratio that Wilson [15] calculates for low RRR gas-cooled copper leads. The ratio for the ICST leads appears to be too large, but this may be due to not having good thermal conductivity data for the copper used in the leads.

The six primary leads for the spectrometer solenoid will carry about 275 A. At this current, the optimum heat leaks down these leads should be about $28 \mathrm{~W}$ per pair. At zero current the six primary leads should have a heat leak of about $14 \mathrm{~W}$ per pair. The tuning leads are designed to carry up to $60 \mathrm{~A}$. A pair of these leads will have a powered heat leak of about $5.4 \mathrm{~W}$. At zero current these leads will have a heat leak of about $2.7 \mathrm{~W}$. In reality the heat flow down the leads of the spectrometer solenoid is larger than the minimum value given by equation 1 . 
The calculation of IL/A for the leads is done by calculating the IL/A of each of the lead sub-sections. The leads used for the MICE spectrometer solenoids typically have three sub-sections. The IL/A for the MICE spectrometer magnet leads can be calculated using the following expression;

$$
\left[\frac{I_{D} L_{L}}{A}\right]_{L E A D}=\left[\frac{I_{D} L_{1}}{A_{1}}\right]+\left[\frac{I_{D} L_{2}}{A_{2}}\right]+\left[\frac{I_{D} L_{3}}{A_{3}}\right]
$$

where $I_{D}$ is the design current for the copper leads, $L_{1}$ is the length of lead section $1, A_{1}$ is the cross-section area of sub-section $1, \mathrm{~L}_{2}$ is the length of lead section $1, \mathrm{~A}_{2}$ is the crosssection area of sub-section $2, \mathrm{~L}_{3}$ is the length of lead section $1, \mathrm{~A}_{3}$ is the cross-section area of sub-section 3 .

The design current used for the magnet copper leads depends on a number of factors. If the current is changing over a relatively short time frame, the design current might be the RMS current for the magnet. For magnets like the coupling magnet or the focusing magnet, one might use the current needed for $200 \mathrm{MeV} / \mathrm{c}$ muons. For the spectrometer solenoid, the design current for the large leads is $275 \mathrm{~A}$. For the leads connected to the tuning coils $I_{D}=60 \mathrm{~A}$. Table 2 below shows the properties of the old $275 \mathrm{~A}$ leads used for spectrometer magnet $2 \mathrm{~A}$, and the new leads used for spectrometer magnet $2 \mathrm{~B}$. For the non-flexible sections the connector cross-section for both leads is the same, but there are some differences in the connector lengths. The flexible portion of the lead for spectrometer magnet 2A is made with \#4-Cable that has 392 strands with a cross-section area of $0.0491 \mathrm{~mm}^{2}$ each. The flexible portion of the lead for spectrometer magnet $2 \mathrm{~B}$ is made with \#2-Cable that has 644 strands with a cross-section area of $0.0491 \mathrm{~mm}^{2}$ each.

Table 2. The Parameter for the Old and New Spectrometer Magnet Copper Leads

\begin{tabular}{lcc}
\hline \hline \multicolumn{1}{c}{ Parameter } & Old Lead & New Lead \\
\hline Length of Section 1 $(\mathrm{m})$ & 0.1524 & 0.127 \\
Area of Section 1 $\left(\mathrm{m}^{2}\right)$ & $3.167 \times 10^{-5}$ & $3.167 \times 10^{-5}$ \\
IL/A of Section 1 $\left(\mathrm{A} \mathrm{m}^{-1}\right)$ & $1.323 \times 10^{6}$ & $1.103 \times 10^{6}$ \\
Length of Section 2 $(\mathrm{m})$ & 0.0254 & 0.050 \\
Area of Section 2 $\left(\mathrm{m}^{2}\right)$ & $7.126 \times 10^{-5}$ & $7.126 \times 10^{-5}$ \\
IL/A of Section 2 $\left(\mathrm{A} \mathrm{m}^{-1}\right)$ & $0.098 \times 10^{6}$ & $0.193 \times 10^{6}$ \\
Length of Section 3 $\left(\mathrm{m}^{6}\right)$ & 0.2642 & 0.2286 \\
Area of Section 3 $\left(\mathrm{m}^{2}\right)$ & $1.925 \times 10^{-5}$ & $3.162 \times 10^{-5}$ \\
IL/A of Section 3 $\left(\mathrm{A} \mathrm{m}^{-1}\right)$ & $3.774 \times 10^{6}$ & $1.988 \times 10^{6}$ \\
\hline IL/A of the Entire Copper Lead $\left(\mathrm{A} \mathrm{m}^{-1}\right)$ & $\mathbf{5 . 1 9 5 \times 1 0 ^ { 6 }}$ & $\mathbf{3 . 2 8 4 \times 1 0 ^ { 6 }}$ \\
\hline \hline
\end{tabular}

* See Figure 9 for a picture of the feed through and the old flexible lead used in Magnet 2A.

The primary purpose of the lead cooler experiment is to measure the heat flow down the copper leads shown in Table 2 with no current in the leads and with $275 \mathrm{~A}$ in the leads. From the measured values of the heat leak, the lead design for the spectrometer solenoid could be set based on the test measurements using the actual copper cable that is used to fabricate the magnet leads. 


\section{The Cooler-Lead Test Experimental Apparatus}

A schematic of the cooler-lead test apparatus is shown in Figure 3. The apparatus consists of a vacuum vessel, a helium tank, a shield and copper top plate, a cooler sleeve, a PT415 cooler that is configured to drop into the cooler sleeve, a pair of copper leads, thermal intercepts for the tops and bottoms of the HTS leads, a pair of HTS leads rated at $500 \mathrm{~A}$ (at $\mathrm{B}=0 \& \mathrm{~T}=64 \mathrm{~K}$ ), a helium vessel feed through, the low $\mathrm{T}_{\mathrm{C}}$ conductor needed to close the lead circuit, and various bits of instrumentation. The leads were powered to $275 \mathrm{~A}$ by a magnet power supply that can produce up to $300 \mathrm{~A}$ at a voltage of $10 \mathrm{~V}$.
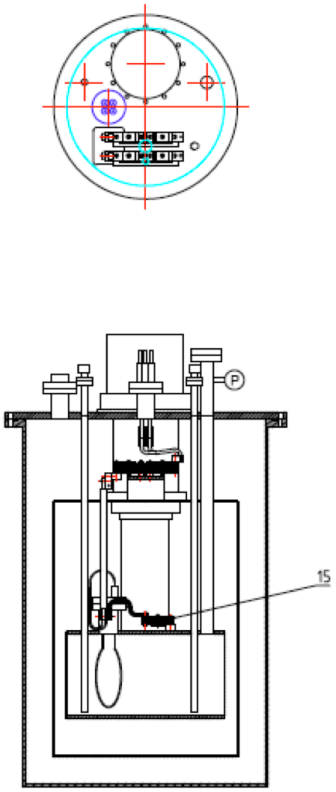
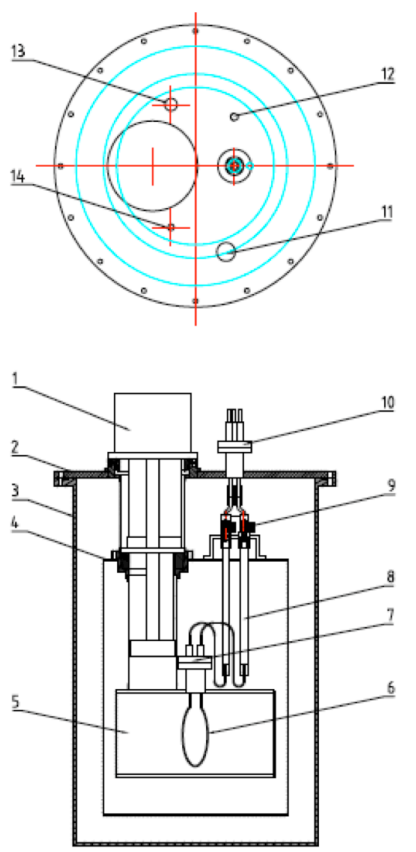

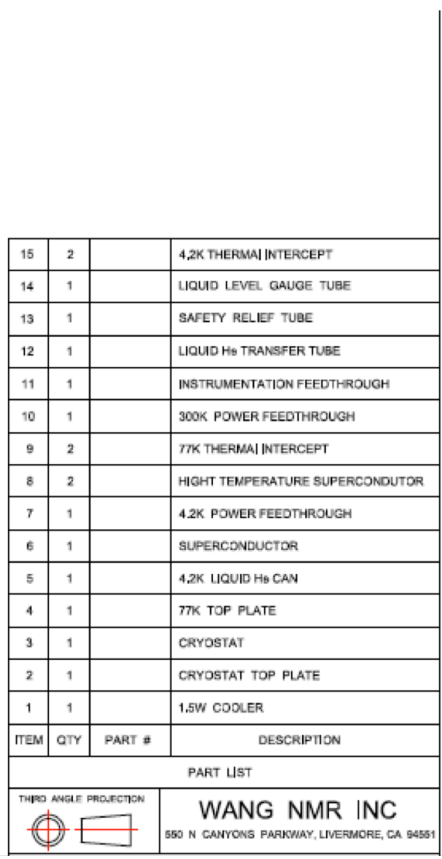

Figure 3. A Schematic Representation of the Cooler-Lead Experiment showing the Primary Parts

There were two primary purposes for the lead-cooler experiment. The first purpose is to measure the thermal performance of the copper leads by measuring the temperature of the cooler first-stage with the leads powered and un-powered.

The second purpose of the test is to measure the voltage drops across various parts of the circuit. With voltage drop measurements one can calculate the $I^{2} R$ heating in the various parts of the circuit. Voltage taps in the circuit permit one to measure the $I^{2} R$ heating of the copper leads, the HTS leads, the joints between the HTS leads and the helium tank feed-through and the joints in the LTS circuit that is inside of the helium tank. The spectrometer solenoid circuits have a number of splices in them between the HTS leads and the superconducting coils. The length of these splices is between 150 and $200 \mathrm{~mm}$. The vendor was concerned that the splice resistance may have a significant contribution to heating of the cold mass assembly. In general, the splices used in the cooler-lead experiment were half the length of the same splices in the spectrometer magnet. In general, the $I^{2} R$ heating of the splices should be inversely proportional to their length [28], [29]. Figure 4 shows an electrical schematic of the cooler-lead experiment. Note: the low temperature superconductor splices shown in Figure 4 are about half of the lengths of the splices installed in magnet $2 \mathrm{~A}$ and magnet $2 \mathrm{~B}$. 


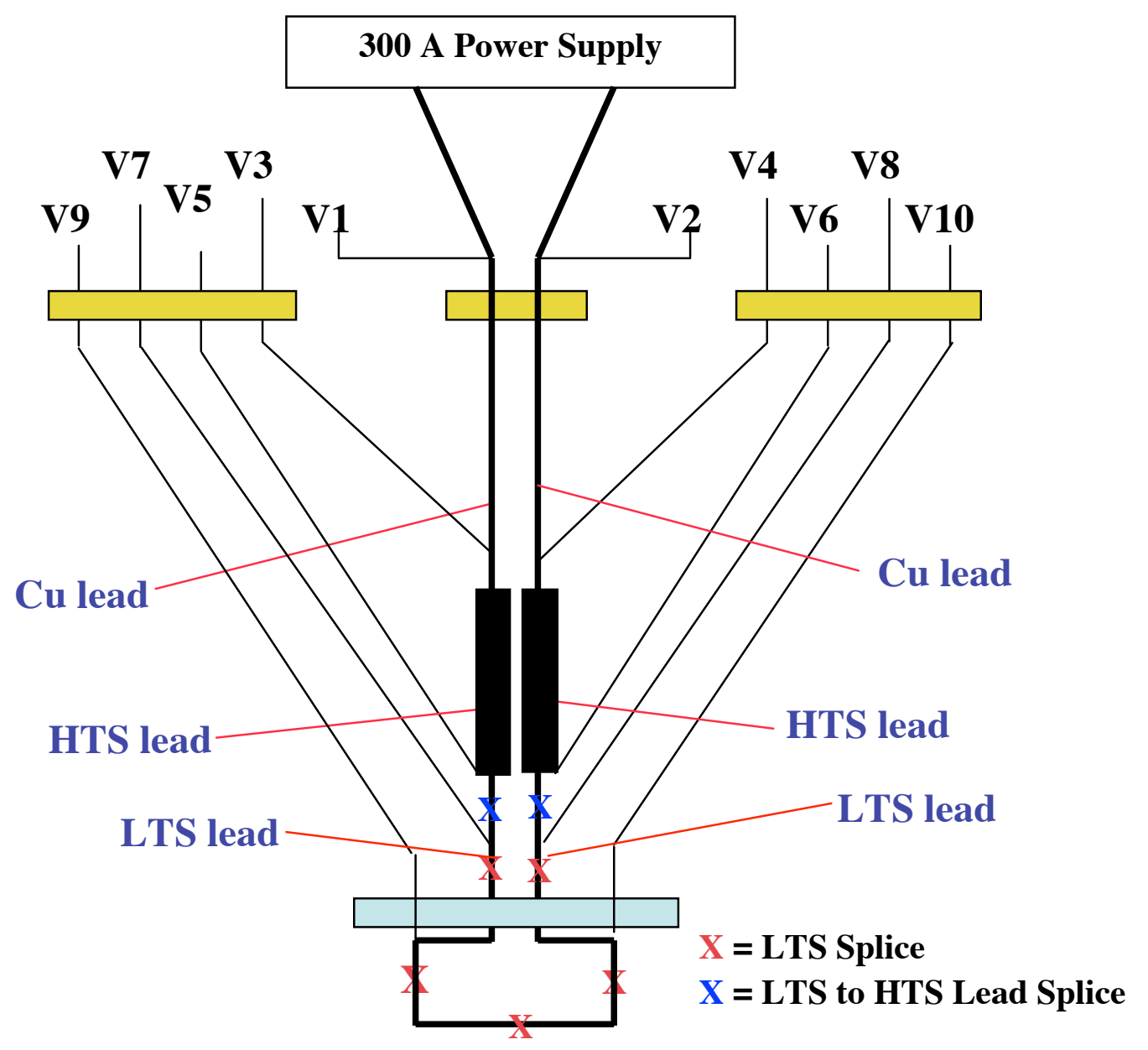

Superconducting Loop

Figure 4. An Electrical Schematic of the Current Lead Circuit with its Voltage Taps

The cooler-lead experiment instrumentation consists of voltage taps, temperature sensors, a pressure gauge to measure the pressure in the helium tank, and a liquid helium level gauge. The voltage taps are to measure the voltage drops in the current circuit as that circuit carries current. The temperature sensors measure temperature at various places in the cooler-lead experiment. The pressure gauge on the helium tank measures the vapor pressure of the helium in the tank. This pressure can be used to calibrate the temperature sensors at $4 \mathrm{~K}$. The liquid level gauge measures the liquid helium level in the tank. This level gauge is good up to tank pressures of 1.8 bars (12 psig).

The location of the voltage taps in the circuit is shown in Figure 4. In general the location of the voltage taps is as follows: V1 is located at the room temperature end of copper lead 1. V2 is located at the room temperature end of copper lead 2. V3 is located between the bottom of copper lead 1 and the top of HTS lead 1. V4 is located between the bottom of copper lead 2 and the top of HTS lead 2. (The exact location of voltage taps V3 and V4 may have an affect on the measured voltage drop in the HTS lead 1 and HTS lead 2.) V5 is located at the bottom of HTS lead 1. V6 is located at the bottom of HTS lead 2. V7 located outside of the vacuum side of feed-through that carries current from HTS lead 1 into the helium tank. V8 located outside of the vacuum side feed- 
through that carries current from HTS lead 2 into the helium tank. V9 is located in the helium tank inside of the feed-through that carried current from HTS lead 1. V10 is located in the helium tank inside of the feed-through that carried current from HTS lead 2. There is a $100 \mathrm{~mm}$ long splice in the low temperature superconductor between voltages taps V9 and V10. In general, all of the voltage taps below the HTS leads (V5, V6, V7, V8, V9 and V10) have low temperature superconducting splices between them. From measured voltage drops and the current, one can determine the approximate resistance of the splices. Voltage taps V3 and V4 may be located some distance from the tops of the HTS leads. As a result, voltage drops from V3 to V5 and V4 to V6 may include some copper that is carrying current.

Temperature sensors $\mathrm{T} 1$ and $\mathrm{T} 2$ are un-calibrated silicon diodes. As a result, the temperature read by these diodes can be in error by $\pm 0.3 \mathrm{~K}$. Silicon diodes are magnetic field sensitive, but that isn't an issue with this experiment. The vapor pressure of the helium in the tank can be used to calibrate sensor T1. Temperature sensor T2 is harder to calibrate because this temperature pulsates. Temperature sensor T1 and T2 should have been calibrated Cernox sensors. Temperature sensors T5 through T9 are platinum resistance sensors. These are well calibrated to about $\pm 0.02 \mathrm{~K}$. The platinum resistance sensors are not good below $18 \mathrm{~K}$. There are no temperature sensors T3 and T4.

The locations of the temperature sensors are as follows: Sensor T1 is located on the liquid helium tank. Sensor T2 is located on the second stage cold head of the cooler. (The temperature of the sensor fluctuates $\sim 0.3 \mathrm{~K}$, because of the pulsing of the gas in an out of the regenerator attached to the cold head.) Sensor T5 is located on the first stage cold head. (There is pulsation of this temperature, but it is only $\sim 0.01 \mathrm{~K}$.) Sensor T6 measures the temperature of the copper plate near the HTS leads. Sensor T7 is located on the copper ring that the tapered section of the cooler first stage drops into. T7 - T5 is the temperature drop across the drop-in joint between the cooler cold head and the copper ring. T7 - T6 is the temperature drop across the copper top plate of the experiment. Sensors T8 and T9 are located on the tops of the HTS leads. T8 - T6 is the temperature drop for the lead thermal-intercept for the heat coming down one copper lead coming down from room temperature. T9 - T6 is the temperature for the lead thermal-intercept for the heat coming down the other copper lead from room temperature. The important thing that one learns from the first-stage temperature sensors is the temperature-drops between the tops of the HTS leads and the cooler first-stage (T8 - T5 and T9 - T5).

Figure 5 shows the cooler-lead experiment as it is being assembled before the shield is installed and before the all of the instrumentation wires have been installed. Figure 6 shows the thermal intercepts for the tops of the HTS leads. These intercepts carry resistive heating and thermal conduction from the copper leads that come down from room temperature to the copper plate while not allowing the leads to be electrically connected to the copper plate. The intercept shown in Figure 6 should hold off a voltage or a couple of hundred volts. Figure 7 shows the region between the copper plate shown in Figure 6 and the top of the helium tank. Figure 8 shows the top of the experiment. Figure 9 shows the vacuum feed-through with a pair of flexible copper leads attached. 

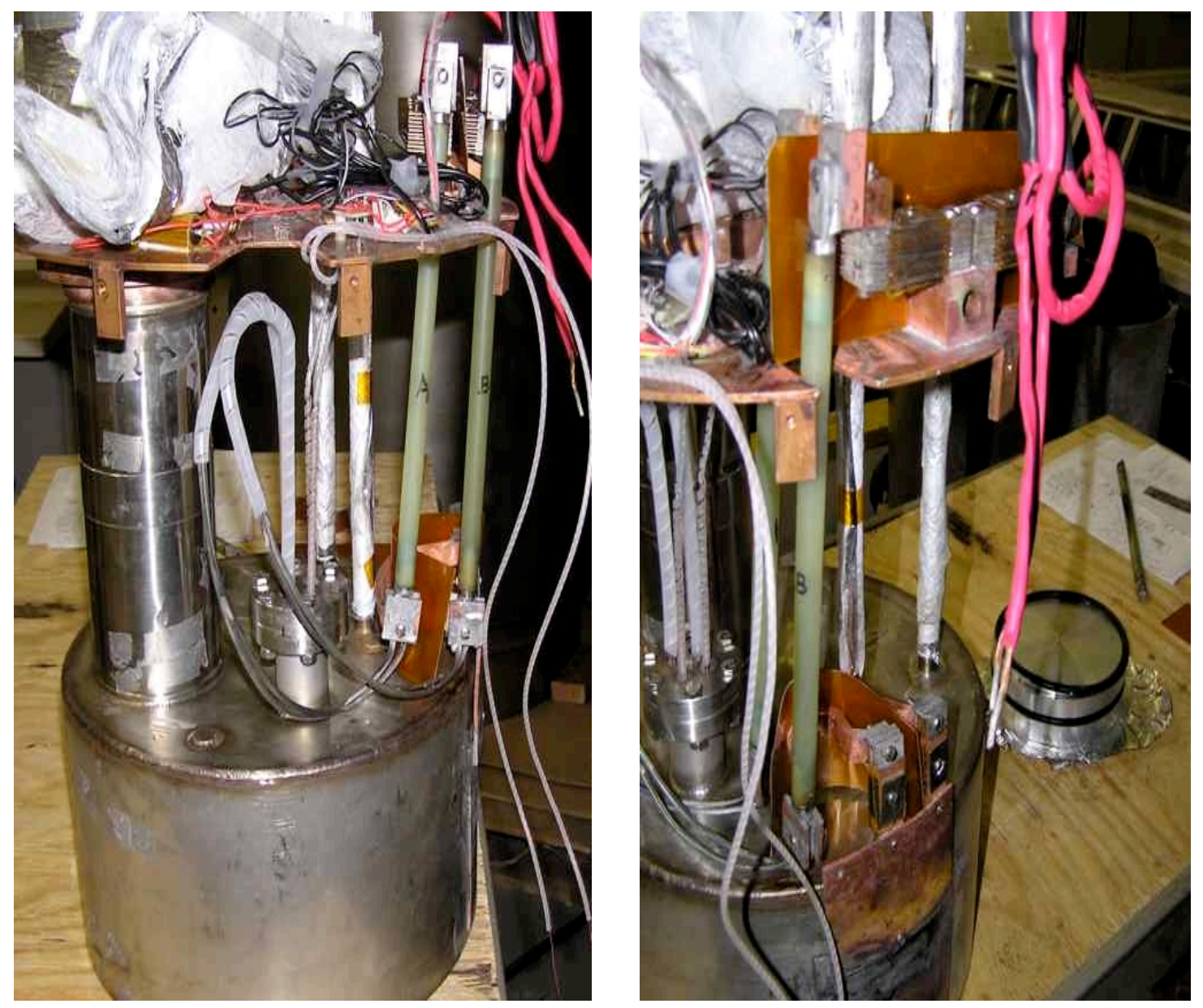

Figure 5. The Lead Cooler Experiment as it is being Fabricated.

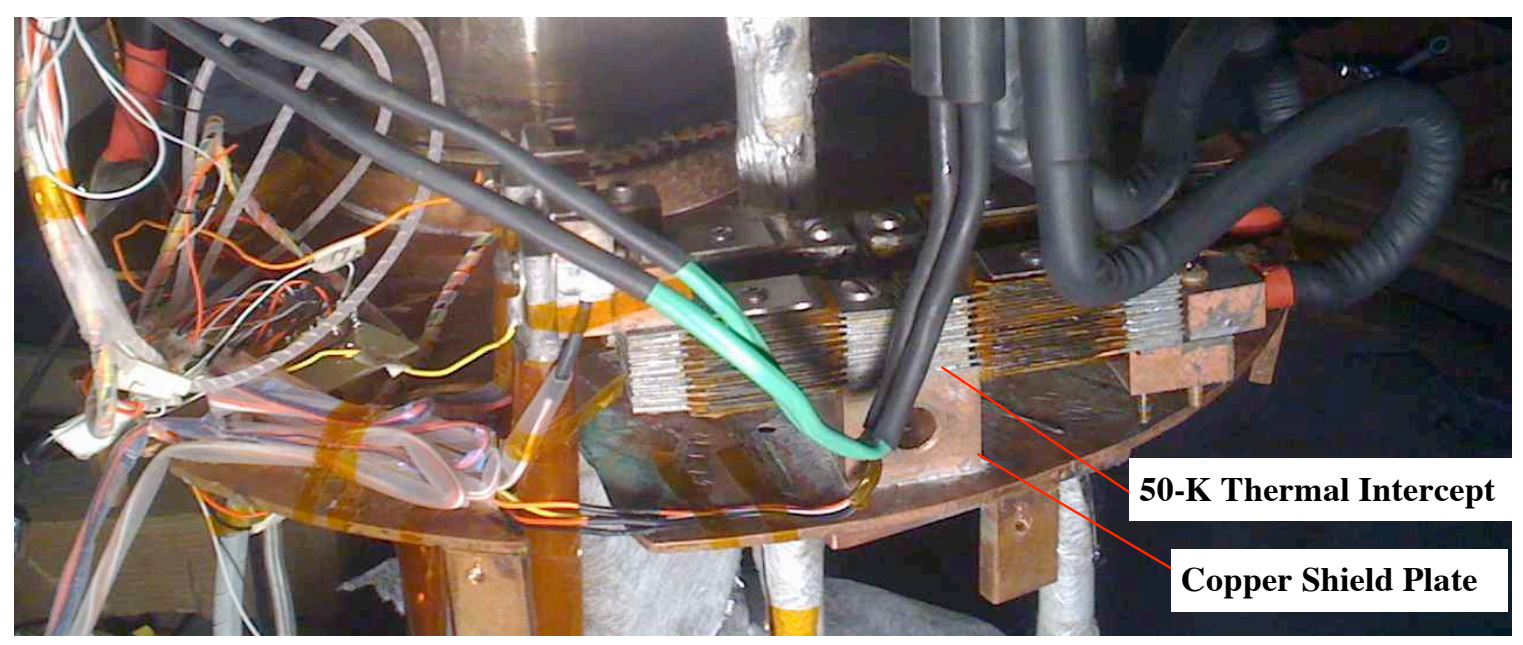

Figure 6. Thermal Intercept to the First Stage Copper Plate for the Leads Coming in from $300 \mathrm{~K}$. (Note: HTS Leads are not installed.) 


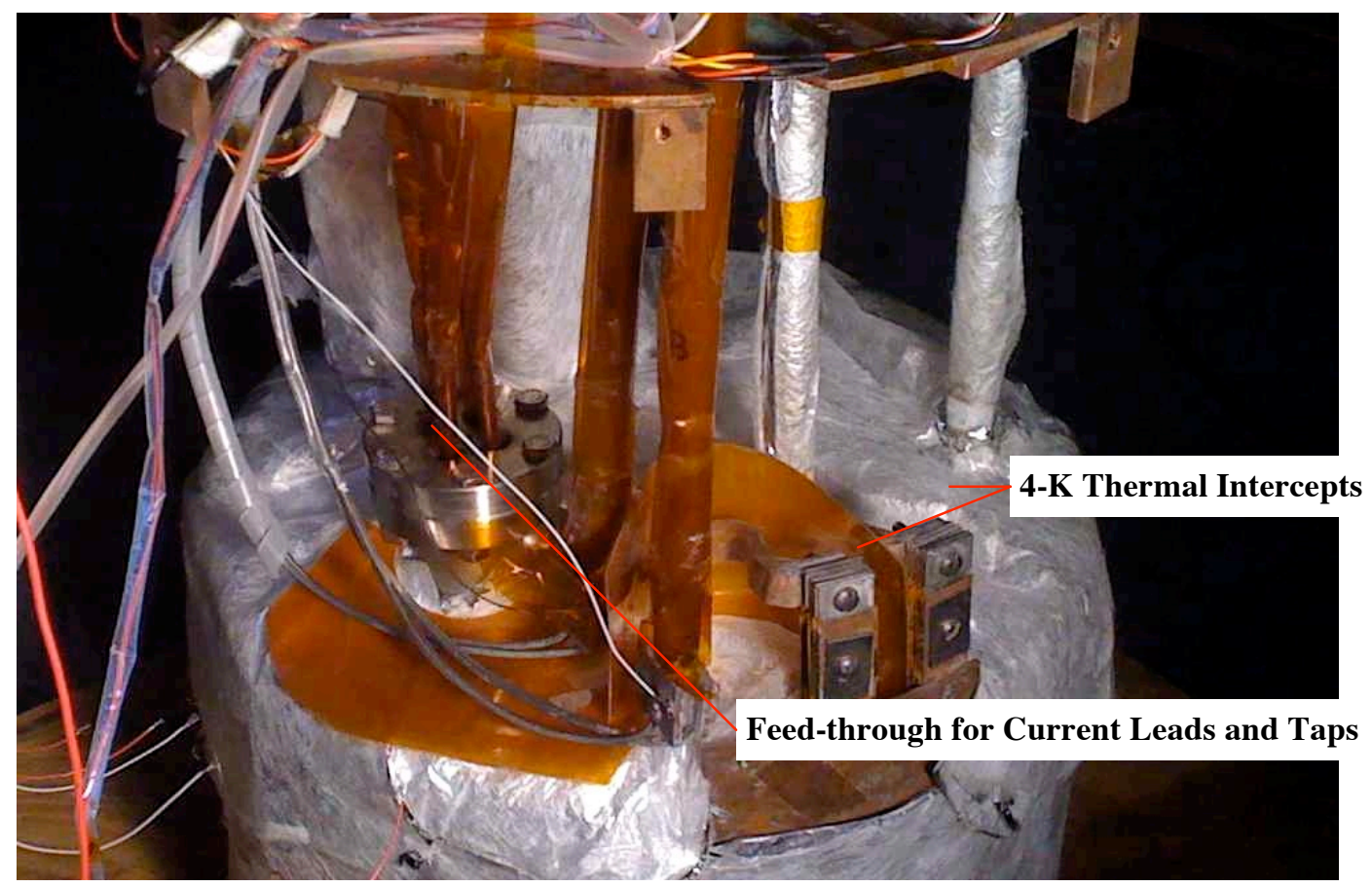

Figure 7. Region between the Copper Plate and the Top of the Liquid Helium Tank. (Note: HTS Leads are not installed.)

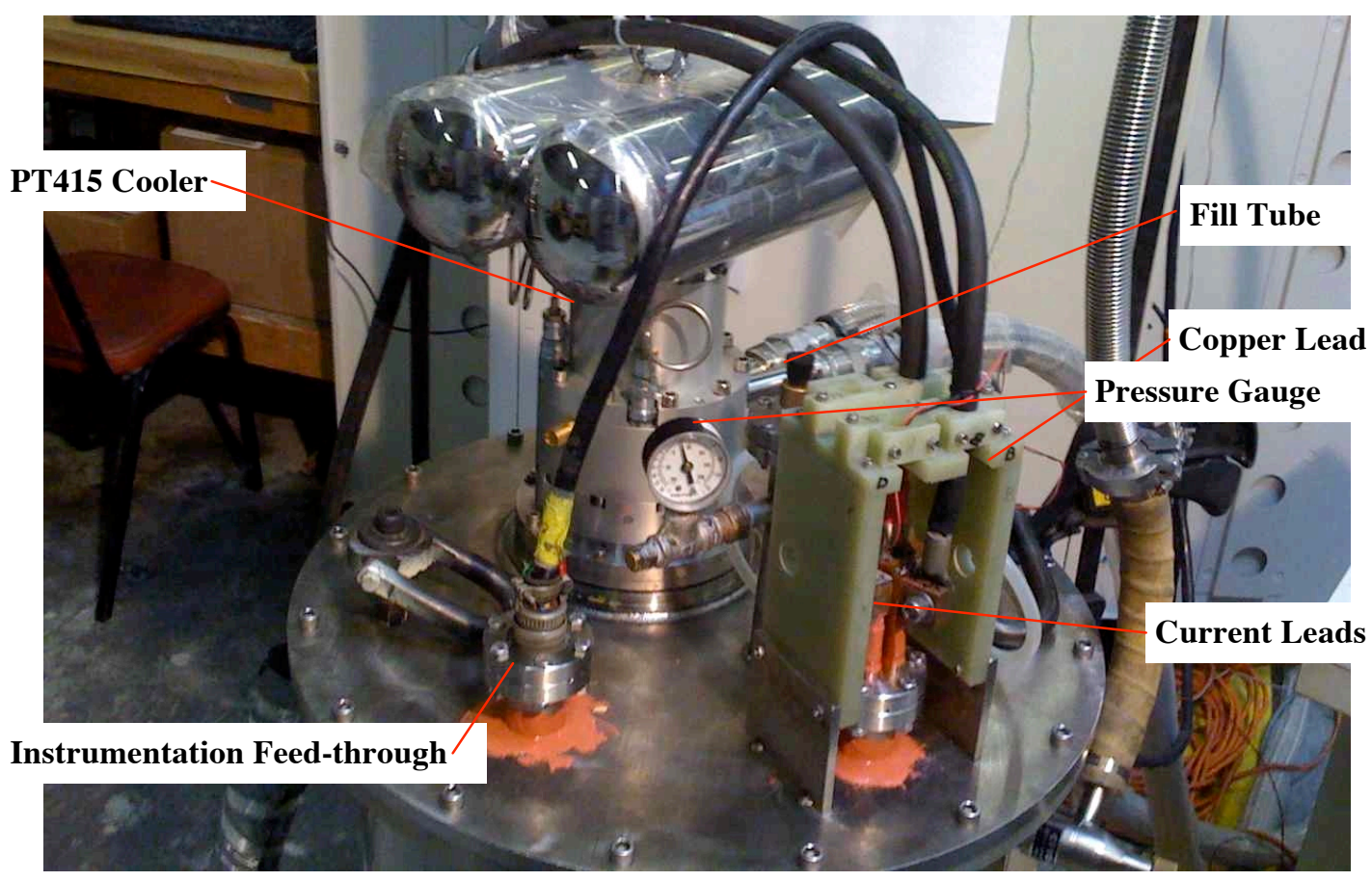

Figure 8. The Top Plate of the Experiment showing the Lead Feed-through, the PT415 Pulse Tube Cooler, the Instrument Wire Feed-through, the Helium Tank Pressure Gauge, and the Fill Tube. 


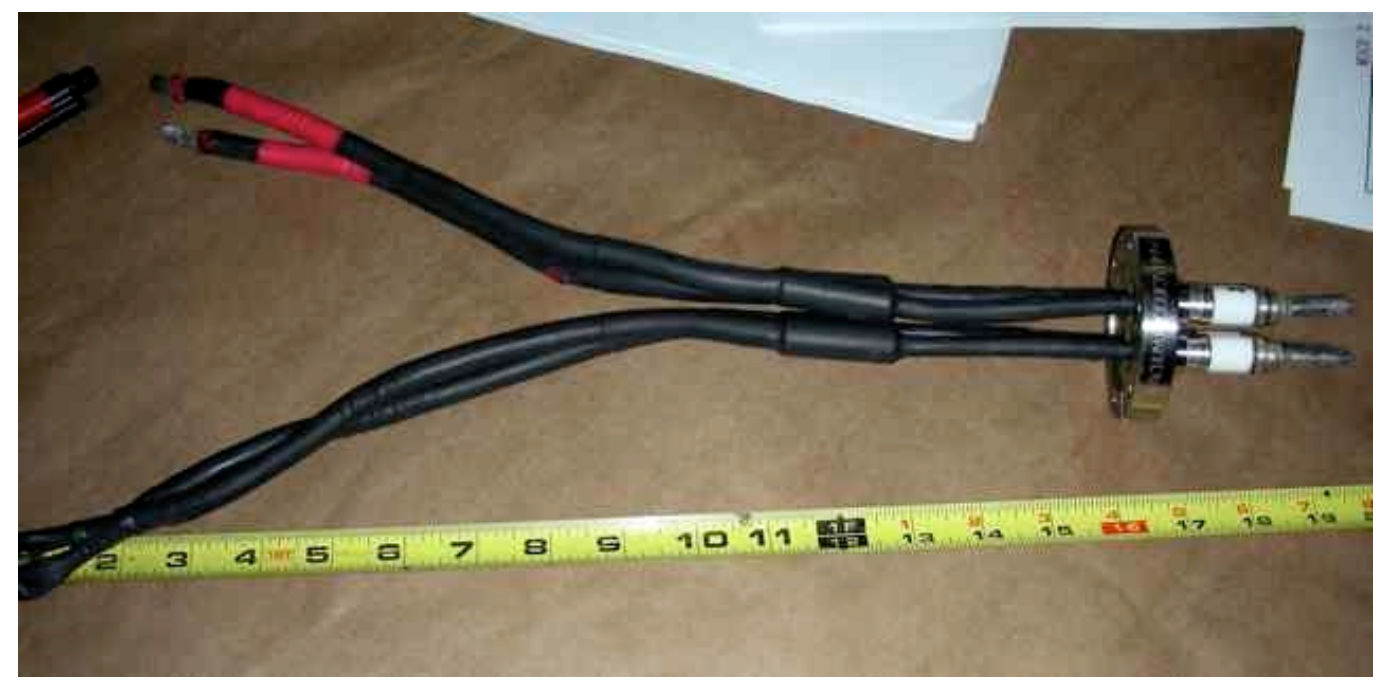

Figure 9. Two Pairs of Flexible Copper Leads Attached to a Vacuum Tight Feed-through for Magnet 2A

There are three tubes that go straight into the liquid helium tank. There is a helium

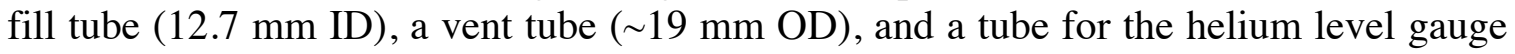
$(\sim 10 \mathrm{~mm}$ ID). These tubes go straight into the helium tank. There is some staging to the shield, but the staging is not very good. These tubes contribute from 0.1 to $0.2 \mathrm{~W}$ to the heat leak into the tank at $4.2 \mathrm{~K}$. The instrumentation wires into the helium tank consists of a pair of voltage taps (the size and composition of these wires are unknown. The heat leak down these voltage taps could be from 0.01 to $0.05 \mathrm{~W}$ depending on the size and composition of the wires. There are four wires that attach to the helium level gauge. The heat leak down these wires is $<0.01 \mathrm{~W}$, when the gauge is off. There are four 24-gauge copper wires that connect to the temperature sensor on cooler second-stage. These wires add $\sim 0.14 \mathrm{~W}$ to the second-stage. The HTS leads add $\sim 0.15 \mathrm{~W}$ of heat to the tank. The cooler sleeve carries from 0.2 to $0.3 \mathrm{~W}$ from the cooler first-stage to a region outside of the condenser. The condenser is about $125 \mathrm{~mm}$ from the top of the liquid helium tank. The sum of the second-stage heat loads is from 0.60 to $0.85 \mathrm{~W}$. From the measured data, the actual heat leak at $4.2 \mathrm{~K}$ is about $0.7 \mathrm{~W}$. The second-stage heat load appears to be independent of the current. A heater attached to the helium tank that will allow one to add up to $1.5 \mathrm{~W}$ of heat into the liquid helium in the tank.

The heat leaks into the first stage through the sleeve are in the range from 2 to $3 \mathrm{~W}$. The instrumentation wire heat leaks to the temperature sensors could be $0.1 \mathrm{~W}$. The heat flow to the shield from the tubes could be from 0.3 to $0.5 \mathrm{~W}$. The heat flow through the MLI is $\sim 1 \mathrm{~W}$. Without the current leads the heat flow into the cooler first stage is in the range from $3.4 \mathrm{~W}$ to $4.6 \mathrm{~W}$. A heater attached to the copper plate can add up to $50 \mathrm{~W}$ of heat into the cooler first-stage. The largest single source of heat flow into the copper plate and the shield is from the copper leads from $300 \mathrm{~K}$. Depending on the current and the design of the leads there can be a lead heat flow up to $45 \mathrm{~W}$ is added with $275 \mathrm{~A}$ flowing in the copper leads. The heat flow from copper lead is current dependent.

A simplified thermal network for the cooler lead experiment is shown in Figure 10. The thermal intercept for the copper leads is more complex than shown in Figure 10. A small amount of IR heating is shunted to the copper plate by added thermal intercepts. 


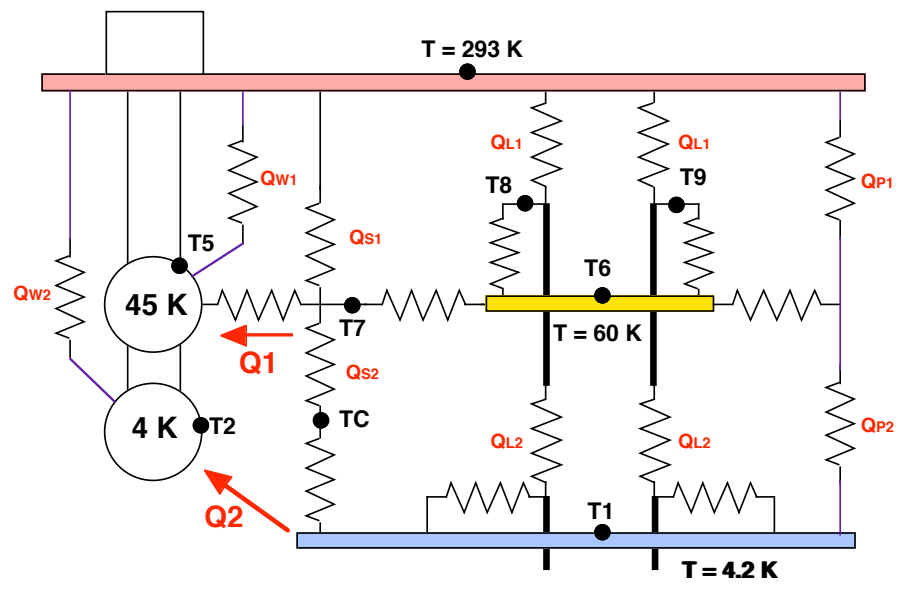

T5 $=$ Cooler 1st Stage Temperature T2 $=$ Cooler 2nd Stage Temperature T7 = Ring Temperature

TC $=$ Temperature Outside of Can

T1 = Tank Temperature

T6 $=$ Shield Temnperature near Leads

T8 = HTS Lead 1 Upper Temperature

T9 = HTS Lead 2 Upper Temperature

QS1 = Sleeve Heat Flow 1st Stage

QS2 = Sleeve Heat Flow 2nd Stage

QW1 = Wire Heat Flow 1st Stage

QW2 $=$ Wire Heat Flow 2nd Stage

QL1 = Lead Heat Flow 1st Stage

QL2 = Lead Heat Flow 2nd Stage

QL2 = Lead Heat Flow 2nd Stage

QP2 = Pipe Heat Flow 2nd Stage

QP2 = Pipe Heat Flow 2nd Stage

Q1 $=$ Heat Flow First Stage

Q2 = Heat Flow Second Stage

Figure 10. The Thermal Network for the Cooler-Lead Experiment

\section{Temperature Calibration of the 4.2 K Diode Sensors}

The two Si-diode temperature sensors were un-calibrated. The Si-diode helium sensor T1 was easy to calibrate, because we measured the saturation pressure of the helium using a pressure gauge. From the picture in Figure 8, one can see that the gauge was quite small. A larger sized gauge or a pressure transducer would have resulted in much better calibration of the diode sensors. The saturation temperature and pressure of two-phase helium was measured in 1908. The best data comes from NIST [30]. The saturation temperature as a function of saturation pressure is plotted in Figure 11.

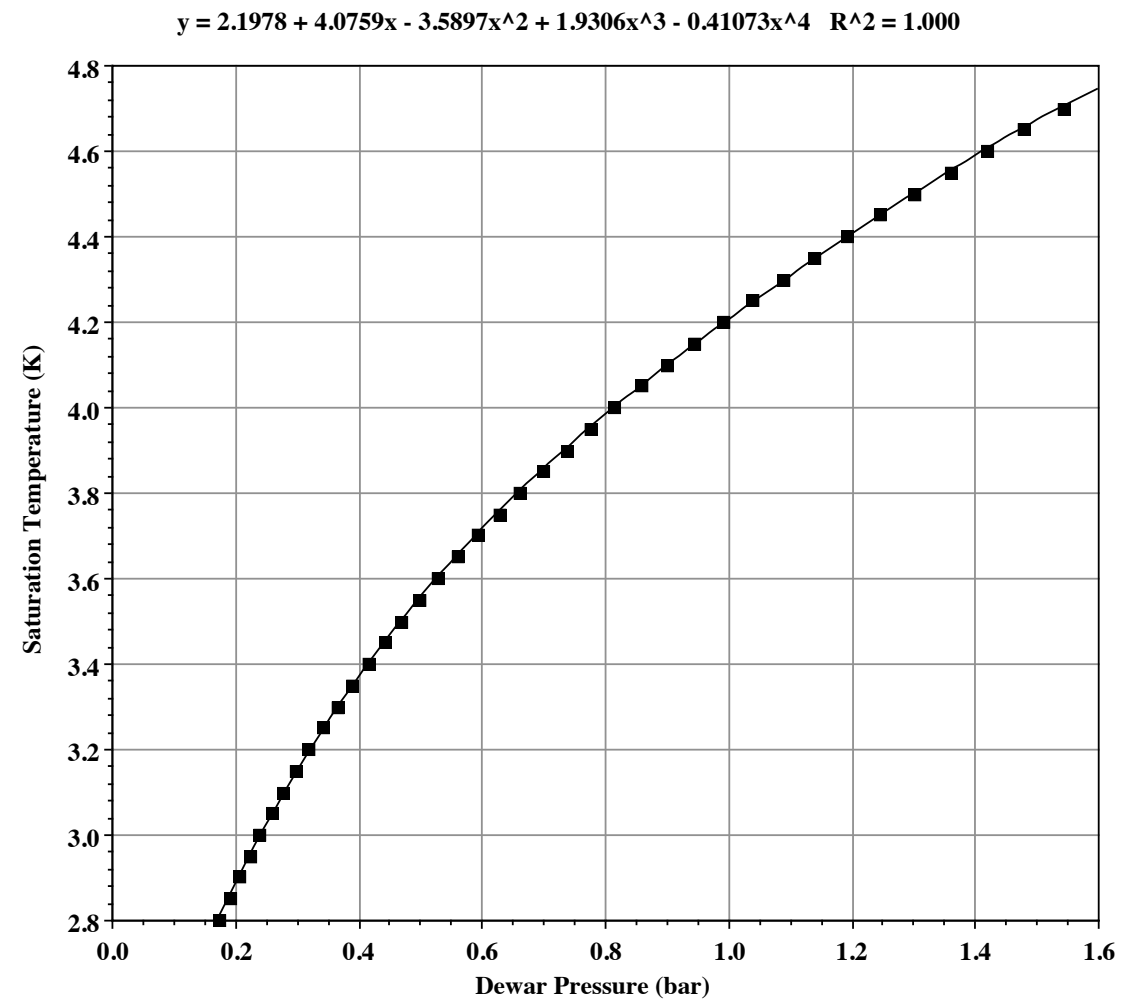

Figure 11. Helium Saturation Temperature as a Function of Pressure 
The equation at the top of Figure 11 is a fourth order polynomial equation that was fitted to the data (from $\mathrm{T}=2.8 \mathrm{~K}$ to $\mathrm{T}=4.8 \mathrm{~K}$ ). The fitting factor for the equation is nearly perfect $\left(R^{2}=1.000\right)$. The equation for the helium saturation temperature $T_{\text {sat }}(K)$ as a function of the saturation pressure $\mathrm{P}_{\text {sat }}$ (given in bars) is as follows;

$$
T_{\text {sat }}=2.1978+4.0759 P_{\text {sat }}-3.5897 P_{\text {sat }}^{2}+1.0306 P_{\text {sat }}^{3}-0.41073 P_{\text {sat }}^{4}
$$

The temperature data for diode $\mathrm{T} 1$ was fitted over a range of pressures from $15 \mathrm{in} \mathrm{Hg}$ (0.504 bar) to 3.5 psig (1.250 bar). As a result, one could come up with an expression that allows one to calibrate Si-diode temperature T1, which is attached to the helium tank. The fitting of the temperature data is illustrated in Figure 12.

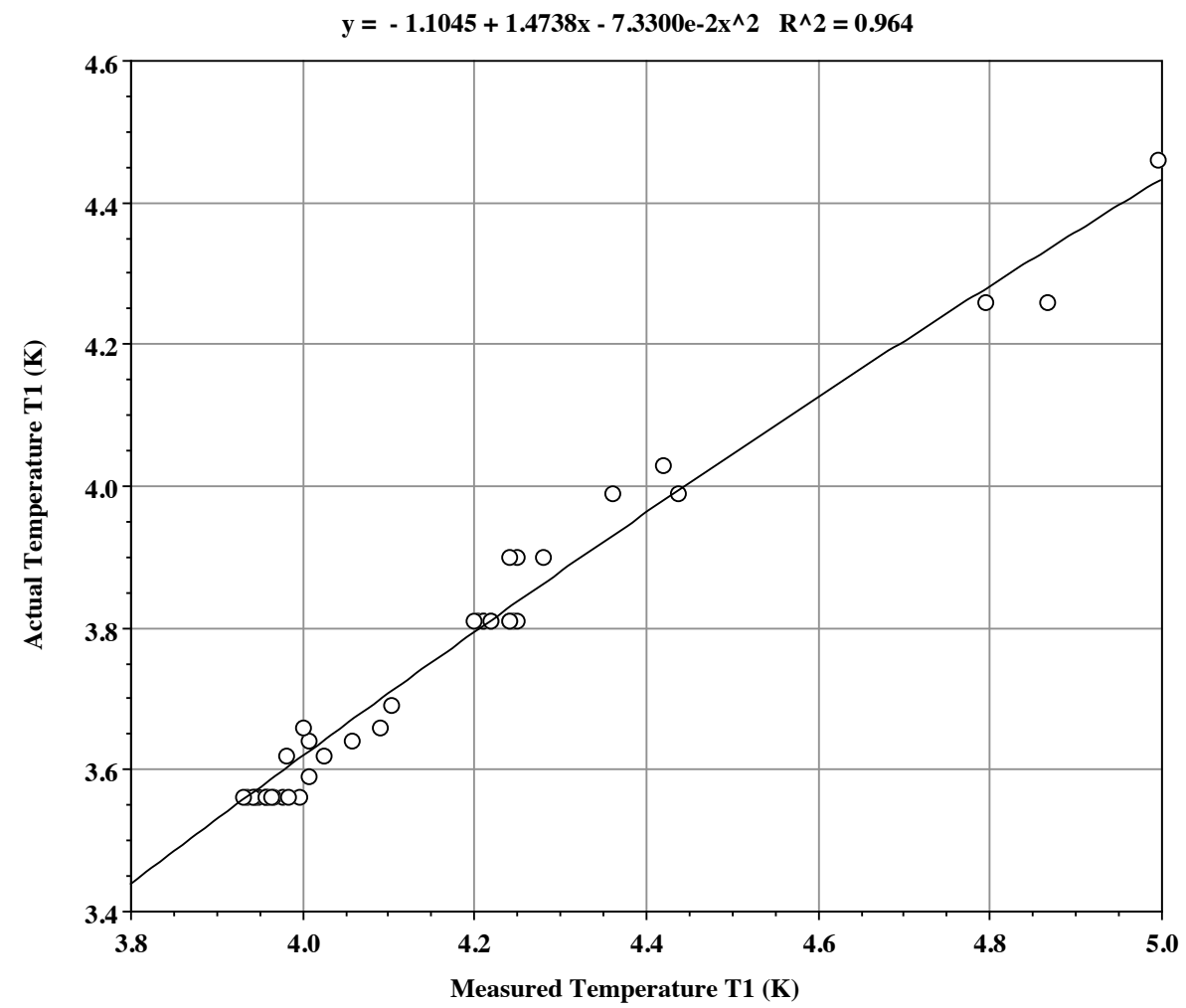

Figure 12. Actual Helium Tank Temperature measured by T1 versus the Measure Tank Temperature on the Meter

The actual diode temperature data for sensor $\mathrm{T} 1$ can be fitted to the measured temperature on the meter using a second order polynomial. The corrected temperature $T_{1 \mathrm{c}}$ as a function of the measured temperature $T_{1 \mathrm{~m}}$ is given by the following expression;

$$
T_{1 c}=-1.1045+1.4738 T_{1 m}-0.0733 T_{1 m}^{2}
$$

Much of the error in the data comes from the fact that the pressure gauge was not very accurate. No attempt was made to calibrate sensor T2. This sensor was attached to the second stage cold head. As a result, the temperature pulsated with the flow of gas in the cold head. However, it was observed that this sensor behaved much like sensor T1. 


\section{The Results of Thermal Tests with the Copper Leads Installed}

The cooler-lead test was first run with the 275 A copper leads that were installed in magnet $2 \mathrm{~A}$. These leads have a nominal IL/A $=5.2 \times 10^{6} \mathrm{~A} \mathrm{~m}^{-1}$. The copper leads used in spectrometer magnet $2 \mathrm{~A}$ were the same leads that were installed in the Superbend magnets at LBNL about ten years ago. The same IL/A was used for the copper leads installed in Venus at LBNL. In all cases, the heat load into the first stage seemed to be too large. The heat load with no current in the leads seemed to be much lower. Since the leads designed by ICST for the coupling magnet have a much lower IL/A [16], there was a suspicion that the magnet $2 \mathrm{~A}$ leads had an IL/A that was too high. Such leads would have a low heat leak with no current in them and a much higher heat leak when they are operated at their full design current.

An attempt was made to determine the source of the temperature drops between the top of the HTS leads and the first-stage of the cooler. In general, the total temperature drop is the sum of the three separate temperature drops: 1) The first temperature drop $\Delta \mathrm{T}_{1}$ is between the copper ring that is hard soldered to the cooler sleeve and the cooler firststage. In Figure 10, $\Delta \mathrm{T}_{1}=\mathrm{T} 7-\mathrm{T} 5$. 2) The second temperature drop $\Delta \mathrm{T}_{2}$ is from a point on the copper plate that is near the HTS lead intercepts to the copper ring attached to the sleeve and the plate. $\Delta \mathrm{T}_{2}$ is the sum of the temperature drop from the copper plate around the sleeve ring to the ring and the temperature drop along the copper plate. In Figure 10, $\Delta \mathrm{T}_{2}=\mathrm{T} 6-\mathrm{T} 7$. The heater attach to the copper plate is between the lead intercept and the ring, which complicated the analysis for cases when the heat is adding heat to the copper plate. 3) The third temperature drop $\Delta \mathrm{T}_{3}$ is the temperature drop from the top of the HTS lead and the copper plate near the copper lead intercepts. In Figure 10, $\Delta \mathrm{T}_{3}=\mathrm{T} 8$-T6 and $\Delta \mathrm{T}_{3}=\mathrm{T} 9$-T6. Each lead intercept can have a different temperature drop.

\section{a) $\Delta T_{1}$ the Ring to Cooler First Stage Temperature Drop}

During the thirteen runs of the cooler-lead test, we were able to measure $\mathrm{DT}_{1}$ in seven of these runs. In a number of cases temperature $\mathrm{T} 7$ sensor failed because it was not properly attached to the sleeve ring. More will be said about this later in this report. The cooler first stage has a 5-degree taper (See Figure 13). This taper fits into a sleeve ring that also has a 5-degree taper. The sleeve ring is silver brazed to the cooler sleeve at the top and bottom. The copper sleeve ring is attached to the copper plate by glue joint.

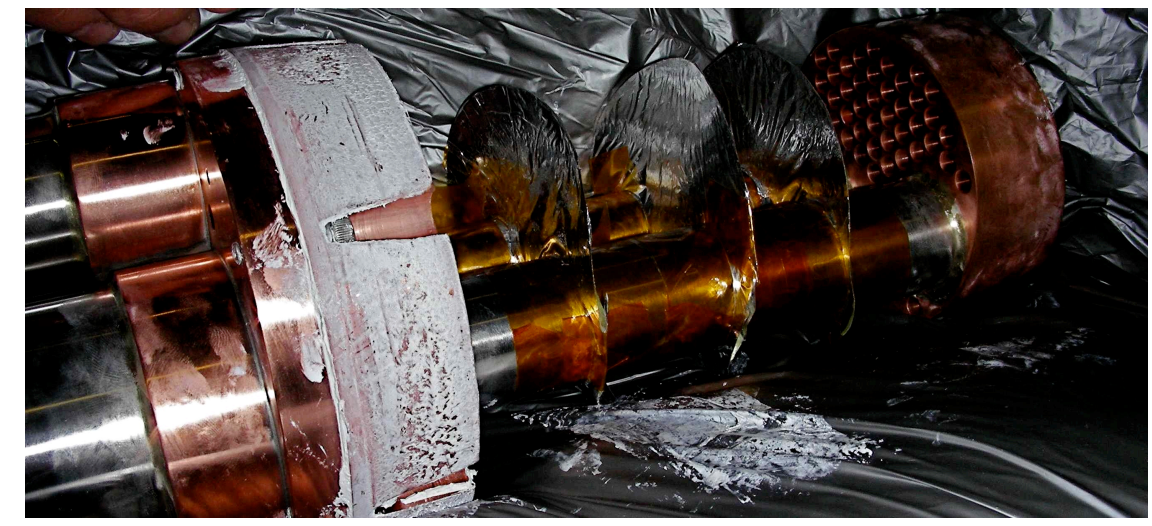

Figure 13. First-stage pressed tapered fit with vacuum grease (left), and second stage condenser (right). 
The taper on the cooler first stage is shown in Figure 13. Figure 13 also shows the high thermal conductivity vacuum grease used to increase the heat transfer coefficient between the ring and the cooler first stage. The baffles between the first stage and the second stage condenser were supposed to improve the performance of the cooler second stage. These baffles did nothing one way or another, so they were dropped in subsequent cooler tests and on the magnets. The sleeve ring arrangement is shown in Figure 14 [31]. Temperature sensor T5 is attached to the cooler first stage and temperature sensor T7 is attached to the sleeve ring. Since the taper attached to the first stage is a separate piece, $\Delta \mathrm{T}_{1}$ includes the $\Delta \mathrm{T}$ between the tapered piece and the cooler first-stage. The method of attachment of the tapered piece is not clear. There is one potential difficulty with arrangement shown in Figure 14; the length of the taper section is exactly the same as the length of the receptacle designed to receive the taper. If there is a fabrication error, the taper might not seat properly. This might be one reason why the grease reduces the $\Delta \mathrm{T}$ between the copper sleeve ring and the cooler first stage by a factor of four [18].

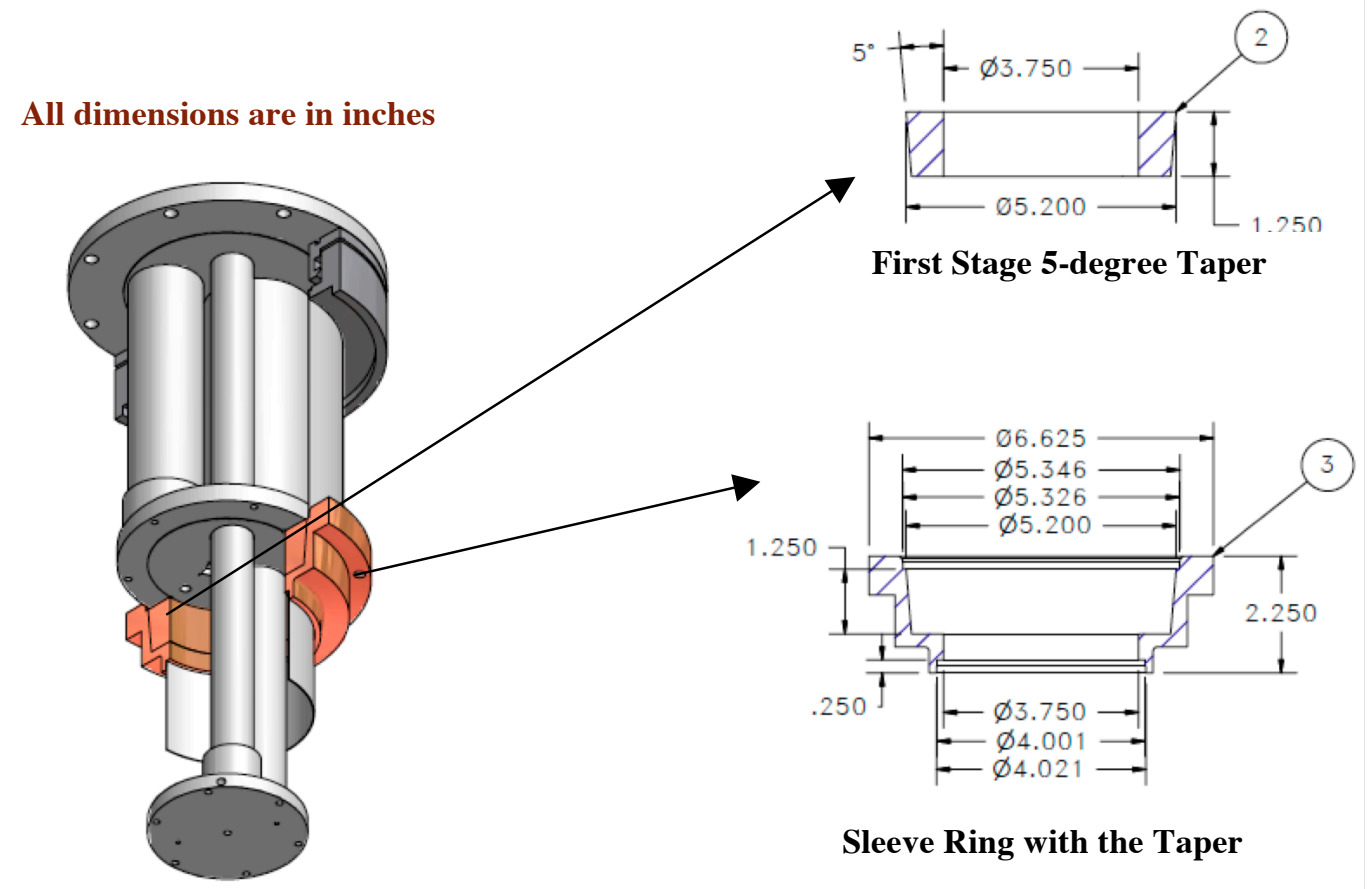

Figure 14. The Tapered Cooler First Stage and the Sleeve Arrangement for the Drop-in Coolers

In the seven cases where $\Delta \mathrm{T}_{1}$ could be measured, one could calculate the $\mathrm{U}$ factor (the heat transfer coefficient) for the joints between the cooler first stage and the cooler sleeve ring. The following expression can be used to calculate the $\mathrm{U}$ factor;

$$
U=\frac{Q_{1}}{A_{T}\left(T_{7}-T_{5}\right)}
$$

where Q1 is the cooler first stage heat flow and $\mathrm{A}_{\mathrm{T}}$ is the area of the taper in Figure 14. $\left(\mathrm{A}_{\mathrm{T}}=0.0129 \mathrm{~m}^{2}\right.$.) Temperature $\mathrm{T} 5$ and $\mathrm{T} 7$ are previously defined (see Figure 10). 
The heat transfer data for the joints between the cooler first stage and the sleeve ring is plotted in three ways in Figure 15, 16, and 17. Figure 15 is a plot of $\Delta \mathrm{T}_{1}$ versus Q1 (the heat flow into the first stage). Figure 16 is plot of the $U$ factor calculated using equation 10 versus Q1. Figure 17 is plot of the $U$ factor versus the cooler first stage temperature T5.

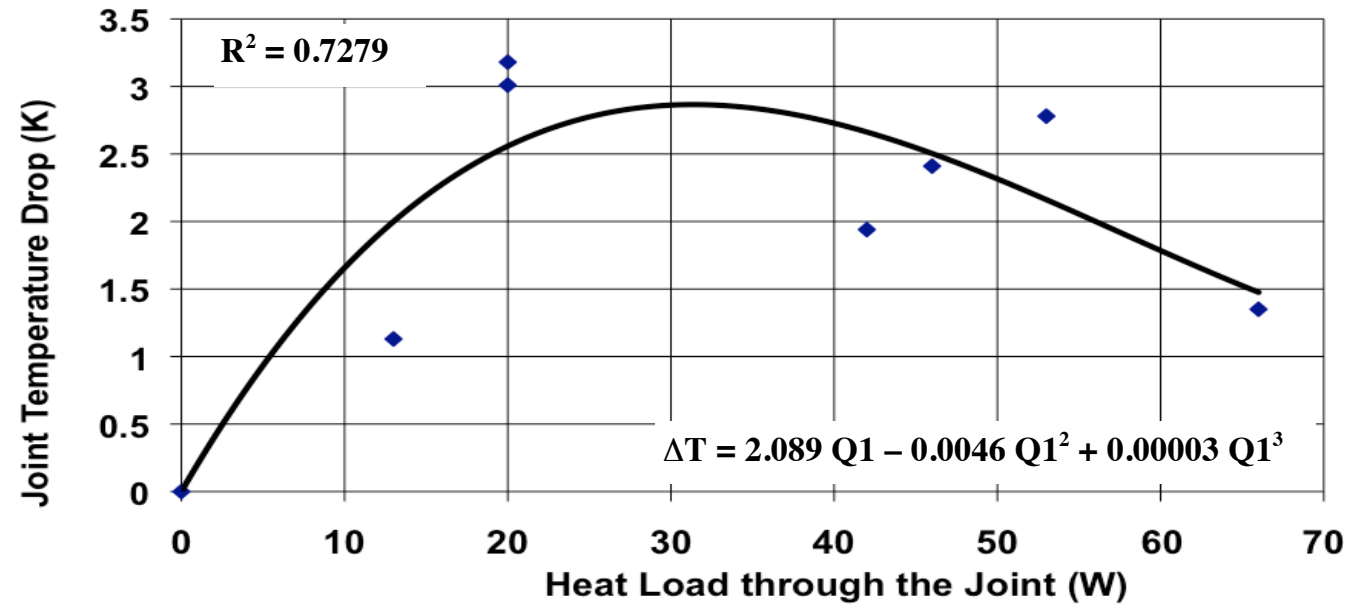

Figure 15. Temperature Drop across the Drop-in Joint as a Function of the First-Stage Heat Load Q1

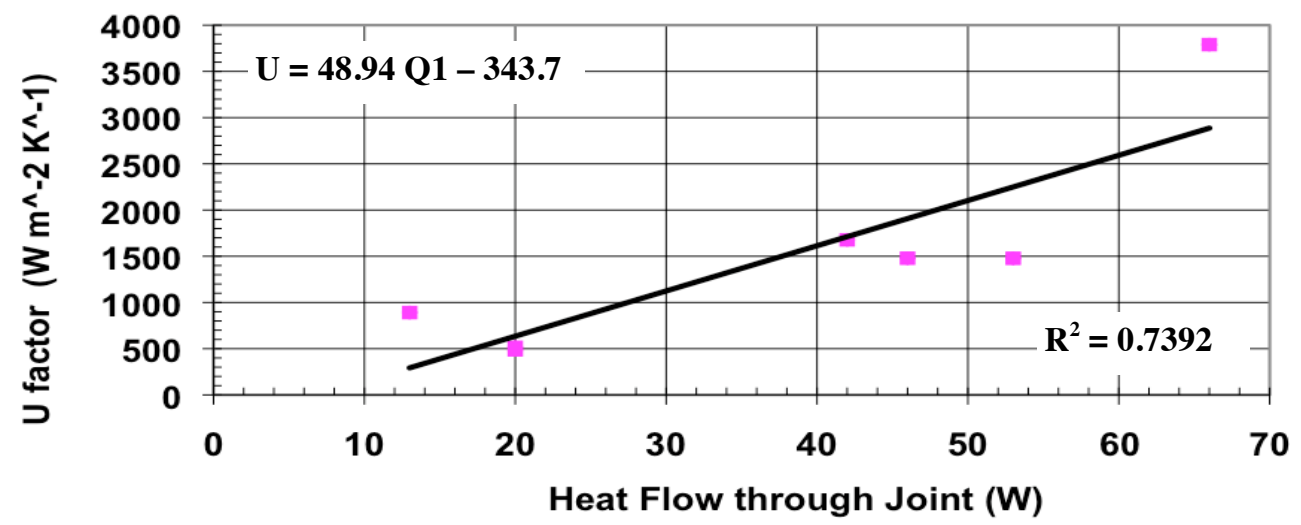

Figure 16. U Factor of the Drop-in Joint as a Function of the First-Stage Heat Load Q1

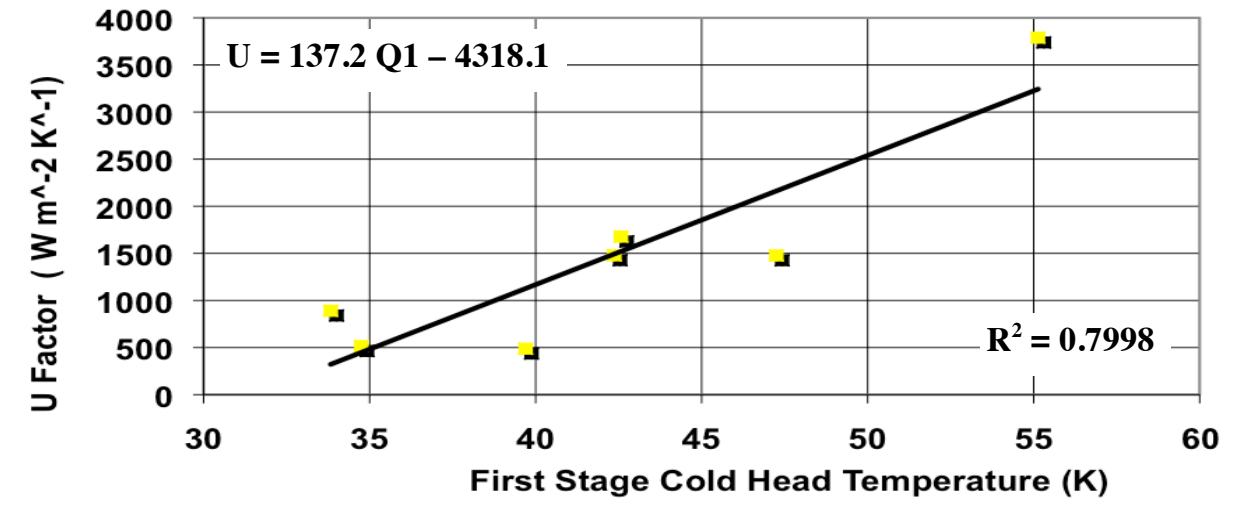

Figure 17. U Factor of the Drop-in Joint as a Function of the First-Stage Temperature T5 
The general trend for the $\Delta \mathrm{T}_{1}$ versus heat load line is that the $\Delta \mathrm{T}$ goes up to a point then it goes down as more heat is put through the joint (see Figure 15). This suggests that the heat transfer $U$ factor goes up as the heat through the joint goes up (see Figure 16). What may actually be happening is the thermal conductivity of the joint goes up with temperature as is shown in Figure 17. This trend is true for both the vacuum grease and any helium gas that may be in the joint. The curve fits for the three plots are given, but the fit is not very good. There is a lot variation in the data, because the cooler and leads were not allowed to come to equilibrium. The people working for the vendor, who were taking the data, were in a hurry, so they didn't follow the test plan that was set up for the experiment. The time constants for the cooler data to come to equilibrium are quite long. These time constants will be discussed later in this report.

\section{b) The Other Two Temperature Drops in the System}

The temperature drop from the top of the HTS lead to a point close to the leads $\Delta \mathrm{T}_{3}$ was measured for ten of the thirteen cases. The temperature drop from the point on the copper plate near the leads to the copper sleeve ring $\Delta \mathrm{T}_{2}$ was measured directly for four of the thirteen cases. Given the equation in Figure 15, one can make an estimate of the temperature drop from the copper plate near the leads to the copper sleeve ring. Temperature drop data for all 13 cases is presented in Table 3 below. Cases 10 and 11 (with a yellow background in Table 3) use the leads and intercepts designed for $60 \mathrm{~A}$. Case 10 was at no current and Case 11 was at $50 \mathrm{~A}$. In the scheme of things, the heat from the leads is not dominant in either of these cases. In Cases 10 and 11 the intercept $\Delta \mathrm{T}$ is larger than one would expect. The area of these intercepts is a factor of 3 smaller.

Table 3. Measured and Estimated Temperature Drops for the Various Leads and Heat Loads

\begin{tabular}{ccccccccc}
\hline $\mathbf{C A S E}$ & $\mathbf{T 5}$ & $\mathbf{Q 1}$ & $\Delta \mathbf{T}_{\mathbf{1}}$ & $\Delta \mathbf{T}_{\mathbf{2}}$ & $\Delta \mathbf{T}_{\mathbf{3 A}}$ & $\Delta \mathbf{T}_{\mathbf{3 B}}$ & \multicolumn{2}{c}{ Total $\Delta \mathbf{T}$} \\
& $\mathbf{( K )}$ & $\mathbf{( W )}$ & $\mathbf{( K )}$ & $\mathbf{( K )}$ & $\mathbf{( K )}$ & $\mathbf{K})$ & $\begin{array}{c}\Delta \mathbf{T}_{\mathbf{T A}} \\
(\mathbf{K})\end{array}$ & $\begin{array}{c}\Delta \mathbf{T}_{\mathbf{T B}} \\
(\mathbf{K})\end{array}$ \\
\hline $\mathbf{1}$ & 33.83 & $\sim 13$ & 1.13 & --- & --- & --- & --- & --- \\
$\mathbf{2}$ & 42.37 & $\sim 46$ & 2.41 & --- & --- & --- & --- & --- \\
$\mathbf{3}$ & 55.13 & $\sim 66$ & 1.35 & --- & --- & --- & --- & --- \\
$\mathbf{4}$ & 35.06 & $\sim 21$ & $\sim 2.5$ & $\sim 5.8$ & 1.07 & 0.99 & $\sim 9.5$ & $\sim 9.4$ \\
$\mathbf{5}$ & 38.43 & $\sim 38$ & $\sim 2.8$ & $\sim 10.7$ & 0.32 & 0.88 & $\sim 13.8$ & $\sim 14.4$ \\
$\mathbf{6}$ & 55.86 & $\sim 68$ & $\sim 1.4$ & $\sim 16.7$ & 0.45 & 1.18 & $\sim 18.1$ & $\sim 18.8$ \\
$\mathbf{7}$ & 42.46 & $\sim 42$ & $\sim 2.7$ & $\sim 3.4$ & 1.11 & 0.61 & $\sim 7.2$ & $\sim 6.7$ \\
$\mathbf{8}$ & 34.75 & $\sim 20$ & 3.01 & 5.12 & 0.74 & 3.10 & 8.87 & 11.23 \\
$\mathbf{9}$ & 42.57 & $\sim 42$ & 1.94 & 15.42 & 10.93 & 5.82 & 28.29 & 23.18 \\
$\mathbf{1 0}$ & 32.62 & $\sim 5$ & $\sim 1.0$ & $\sim 1.7$ & 0.96 & 2.35 & $\sim 3.7$ & $\sim 5.0$ \\
$\mathbf{1 1}$ & 32.83 & $\sim 7$ & $\sim 1.4$ & $\sim 1.8$ & 1.56 & 2.66 & $\sim 4.8$ & $\sim 5.8$ \\
$\mathbf{1 2}$ & 39.70 & $\sim 20$ & 3.18 & 3.09 & 3.24 & 4.40 & 9.51 & 10.67 \\
$\mathbf{1 3}$ & 47.25 & $\sim 53$ & 2.78 & 9.11 & 2.45 & 7.66 & 14.34 & 19.55 \\
\hline
\end{tabular}


The data in Table 3 shows that in most cases $\Delta \mathrm{T}_{2}$ is the dominant temperature drop in the system. The copper plate between the lead intercepts and the sleeve ring is not thick enough. $\Delta \mathrm{T}_{2}$ is further increased by the $\Delta \mathrm{T}$ across the connection between the sleeve ring and the copper plate. The lead intercepts to the copper plates put the heat from the lead into a region of the plate with a relatively small area, which further increases $\Delta \mathrm{T}_{2}$. In cases when the system was allowed to come to equilibrium (cases 1 through 7), the temperature drops across the lead thermal intercepts were quite low. In cases where temperature measurements were taken before the system came to equilibrium (as a result of ignoring the test plan), the values $\Delta \mathrm{T}_{3}$ varied all over the place. It appears that lead wires coming into one of the lead intercept temperature sensors were not properly attached to the surface where the sensor was measuring the temperature. This may explain some of the differences in the $\Delta \mathrm{T}_{3}$ for leads $\mathrm{A}$ and $\mathrm{B}$. In case 6 where an added $30 \mathrm{~W}$ was put in by a heater, the value of $\Delta \mathrm{T}_{2}$ was high. The placement of the heater on the copper plate may have been a factor in the high $\Delta \mathrm{T}_{2}$. Other places where $\Delta \mathrm{T}_{2}$ was high may have been due to the fact that the system was not allowed to come to equilibrium, because the data takers were in a hurry and they didn't follow the test plan. The cooler and lead experiment test plan can be found in the Appendix of this report.

When one looks at the total temperature drops from the tops of the HTS leads to the first stage cold head, the temperature drops are much higher than they should be. High total temperature drops are of less concern for the spectrometer solenoid than any of the other MICE cooling channel magnets. The HTS leads can operate at a higher temperature in the spectrometer solenoid than in any of the others solenoids because the magnetic field at the tops of the HTS leads is much lower than for any of the other MICE cooling channel magnet. The spectrometer solenoid can also use a large single stage GM cooler to bring the temperature of the copper plate down. This option is not available for any of the other magnets in the MICE cooling channel, because GM coolers will not operate in the stray magnetic field from those magnets.

\section{c) The Cooler-lead Test Time Constants}

One can determine the heat flow into the cooler first-stage by knowing the cooler first-stage temperature. One can determine the heat flow into the second stage by knowing the second-stage temperature. In order for one to have a good measurement of the heat flow into the either of the cooler stages, one must allow the system to come to equilibrium. The cooler stages have different time constants. The time constants are determined by the material specific heat and mass as well as the available cooling power from the stage being considered for the calculation. One can estimate the time constant $\tau$ for temperature changes in the system by the following expression;

$$
\tau=\frac{\sum_{1}^{n}\left(C_{P 1} M_{1}+C_{P 2} M_{2}+\ldots \ldots . .+C_{P n} M_{n}\right)}{Q_{a v}}
$$

where $C_{V n}$ is the specific heat at constant volume for constituent $n ; M_{n}$ is the mass of constituent $\mathrm{n} ; \Delta \mathrm{T}$ is the temperature change that is occurring; and $\mathrm{Q}_{\mathrm{av}}$ is the available refrigeration for making the temperature change. ( $\mathrm{Q}_{\mathrm{av}}$ has the same sign as $\Delta \mathrm{T}$.) The time needed for the system to come to equilibrium is about four time constants. 
At the operating temperature of the cooler first stage the specific heat for the copper plate and the experiment shield is roughly ten percent of the room temperature value. When the cooler first stage is operating at a capacity of $40 \mathrm{~W}$ (at $\sim 40 \mathrm{~K}$ ), the specific heat per unit mass for copper is $\sim 50 \mathrm{~J} \mathrm{~kg}^{-1} \mathrm{~K}^{-1}$. When the HTS leads operate at their design temperature $(64 \mathrm{~K})$, the capacity of the cooler cooling the experiment is $\sim 60 \mathrm{~W}$ and the specific heat per unit mass for copper [32], [33] is $\sim 110 \mathrm{~J} \mathrm{~kg}^{-1} \mathrm{~K}^{-1}$. (At $293 \mathrm{~K}$, copper has a specific heat of copper is $\sim 385 \mathrm{~J} \mathrm{~kg}^{-1} \mathrm{~K}^{-1}$ ) The mass of the cooler first-stage, the copper top plate and the shield is about $35 \mathrm{~kg}$. The available refrigeration for changing the temperature of the cooler first stage and the mass attached to the first stage is about five percent of the capacity of the cooler first-stage at the temperature where changes are being made. Small changes at $40 \mathrm{~K}$ will have a time constant of $\sim 880$ seconds. Changes at $60 \mathrm{~K}$ will have a time constant of $\sim 1080$ seconds. The time to come to equilibrium for anything attached to the first stage will be from 1.1 to 1.5 hours. When one looks at the MICE spectrometer solenoid, with a shield and copper plate mass of $400 \mathrm{~kg}$, one might expect the system to come to equilibrium in $\sim 9$ hours with shield at $70 \mathrm{~K}$ when three PT415 coolers provide the first stage cooling. If the shield is warmer, the time to come to equilibrium will be longer. Adding a AL-300 single stage cooler to the three PT415 coolers will reduce the time to come to equilibrium for the spectrometer solenoid shield system to about 4 hours.

At the operating temperature of the cooler second-stage (from 3.8 to $4.6 \mathrm{~K}$ ), the specific heat of solid materials that make up the helium tank and materials attached to the tank is very low. At $4.2 \mathrm{~K}$ copper has a specific heat per unit mass [32] of $\sim 0.1 \mathrm{~J} \mathrm{~kg}^{-1} \mathrm{~K}^{-}$ 1. Liquid helium has a specific heat [30] at constant pressure $C_{P}=\sim 5170 \mathrm{~J} \mathrm{~kg}^{-1} \mathrm{~K}^{-1}$ and a specific heat at constant volume $\mathrm{C}_{\mathrm{V}}=\sim 2560 \mathrm{~J} \mathrm{~kg}^{-1} \mathrm{~K}^{-1}$. The solid material in the tank and the things attached to the tank has a mass of about $30 \mathrm{~kg}$. The helium in the tank has a mass of about $2.2 \mathrm{~kg}$. Virtually all of the enthalpy change at $4.2 \mathrm{~K}$ is due to the liquid helium in the tank. If one wants to change the temperature by $0.1 \mathrm{~K}$ the refrigeration available to change that temperature is about $0.1 \mathrm{~W}$. The resulting time constant for making changes in the temperature of anything connected to the helium tank is $\sim 11000$ seconds along the saturated liquid line. One can expect the $4.2 \mathrm{~K}$ part of the lead cooler test to come to equilibrium in $\sim 12$ hours. When the spectrometer solenoid runs on three PT415 coolers with $22 \mathrm{~kg}$ of liquid helium in the tank, the time for the helium system to come to equilibrium is $\sim 40$ hours.

\section{d) A Summary of the Thermal Tests with and without Current in the Leads}

The lead test was first run with copper leads that were made for magnet 1A and magnet 2A (see Figure 9 and old leads in Table 2). The design IL/A for these leads at $275 \mathrm{~A}$ is given in Table 2 as the old leads. This IL/A is about $5.2 \times 10^{6} \mathrm{~A} \mathrm{~m}^{-1}$. The test of the old leads was done with no current in the leads, with $275 \mathrm{~A}$ in the leads, and with an added heat load to the shield of $20 \mathrm{~W}$ with $275 \mathrm{~A}$ in the leads. The lead test was run again with the new copper leads that were used in magnet $2 \mathrm{~B}$. The design IL/A for these leads was about $3.3 \times 10^{6} \mathrm{~A} \mathrm{~m}^{-1}$ (see the new leads in Table 2). The test of the new leads was done with no current in the leads, with $275 \mathrm{~A}$ in the leads, with $275 \mathrm{~A}$ in the leads plus $30 \mathrm{~W}$ of added heat to the copper plate, and with no added heat to the copper plate with 275 A flowing through the leads. The thermal performance for the two different lead pairs is plotted on cooler operating diagram (see Figure 2) in Figure 18. 


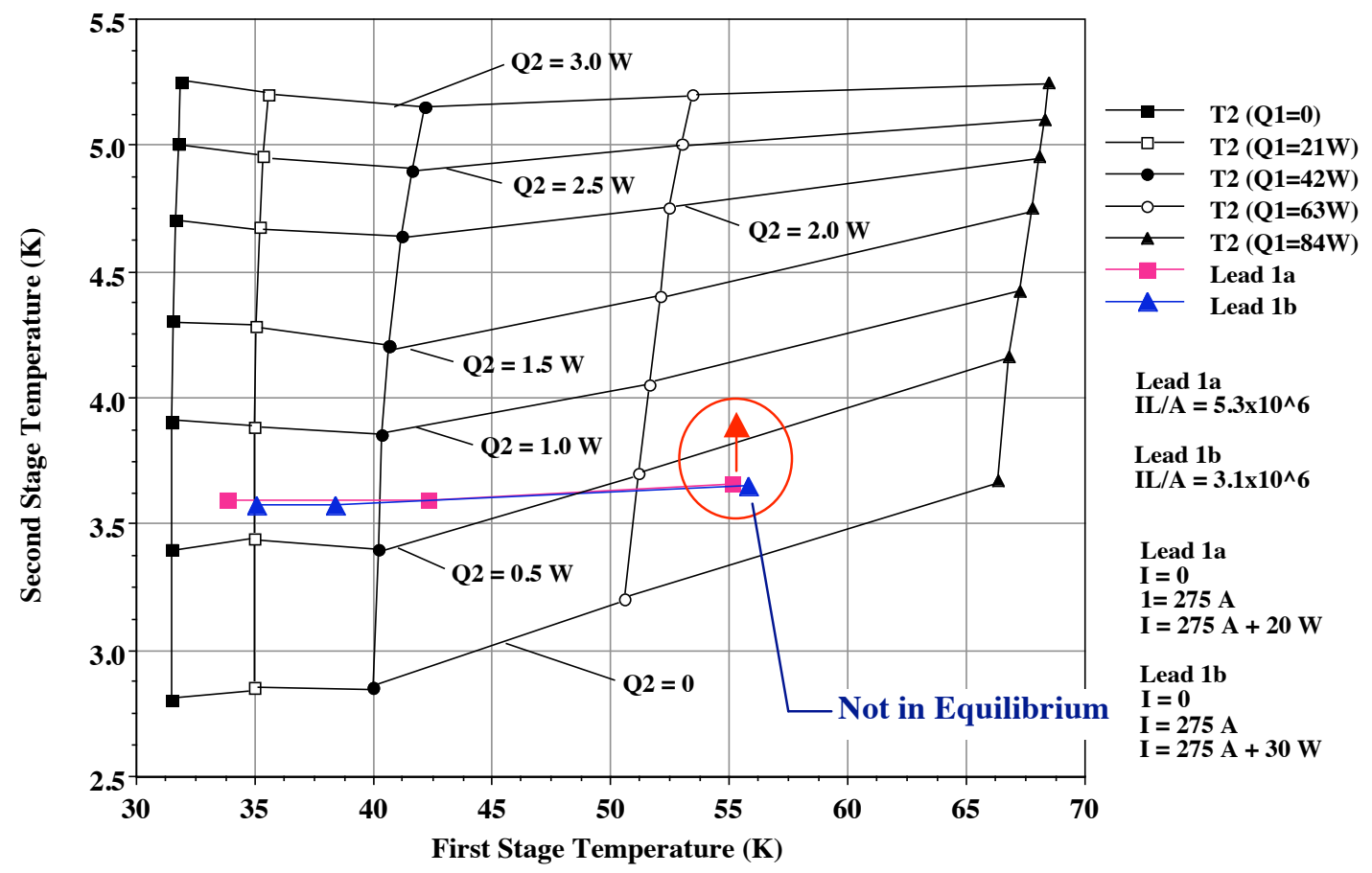

Figure 18. The Performance of Two Different Copper Leads with Different Design IL/As plotted on the Operating Diagram for a Typical PT415 Cooler (see Figure 2)

Figure 18 shows the measured temperature of the cooler first-stage and the average cooler second-stage temperature as inferred from the saturation pressure of the helium in the tank. The first data points with not current in the leads were obtained after waiting until the helium tank reached it lowest possible temperature (over night). The second test points were obtained after the leads were powered to $275 \mathrm{~A}$. The data taker waited about four hours. The first-stage temperature reached equilibrium, but the second-stage temperature may not have reached equilibrium. There was virtually no change in the helium tank pressure between the first and second data point on each curve. After the data was taken for the second point, heat was added to the copper plate. The data taker waited about three hours before taking the third data point. At this time, the helium tank pressure was still going up, which suggests that the temperature was not at equilibrium. The author believes that there should be an increase in the second-stage temperature. Table 4 shows the estimated heat flow down a pair of copper leads of each type. To calculate the values in Table 4 subtract $4 \mathrm{~W}$ from the first-stage heat load in Figure 18.

Table 4. The Estimated Heat Flow down a Pair of Copper Leads from 293 K into a Single PT415 Cooler First-Stage with and without Current (See Figure 18.)

\begin{tabular}{cccc}
\hline \multirow{2}{*}{ Lead } & \multirow{2}{*}{ Il/A } & \multicolumn{2}{c}{ Lead Pair Heat Leak $(\mathbf{W})$} \\
& & $\mathbf{I = 0 ~ \mathbf { ~ A ~ }}$ & $\mathbf{I = \mathbf { 2 7 5 } \mathbf { A }}$ \\
\hline $1 \mathrm{a}$ & $5.2 \times 10^{6}$ & 8 & 42 \\
$1 \mathrm{~b}$ & $3.3 \times 10^{6}$ & 16 & 31 \\
\hline
\end{tabular}


From Table 4 it can be concluded that lead $1 \mathrm{~b}$ is close to optimum in its performance. The IL/A is very close to the value of optimum IL/A calculated by the ICST group in Harbin for the coupling coil leads [16]. The ICST calculations are based on a lead with an RRR $=10$. The RRR for the copper used in the leads $1 \mathrm{~b}$ could be higher than 10. A lead with a higher RRR will have a higher IL/A.

The performance of four pairs of leads of the $1 \mathrm{~b}$ type (IL/A $=3.3 \times 10^{6} \mathrm{~A} \mathrm{~m}^{-1}$ ) is plotted on the operating diagram for a PT415 cooler in Figure 19. One of the four pairs of leads is the $1 \mathrm{~b}$ pair of leads that is shown in Figure 18. Lead pairs 2, 3, and 4 are nominally of the same design as lead pair $1 \mathrm{~b}$ with a nominal IL/A $=3.3 \times 10^{6} \mathrm{~A} \mathrm{~m}^{-1}$. Each lead in the pairs shown in Figure 19 is slightly different, but on the relative scale of things that affect the performance difference should not be very great.

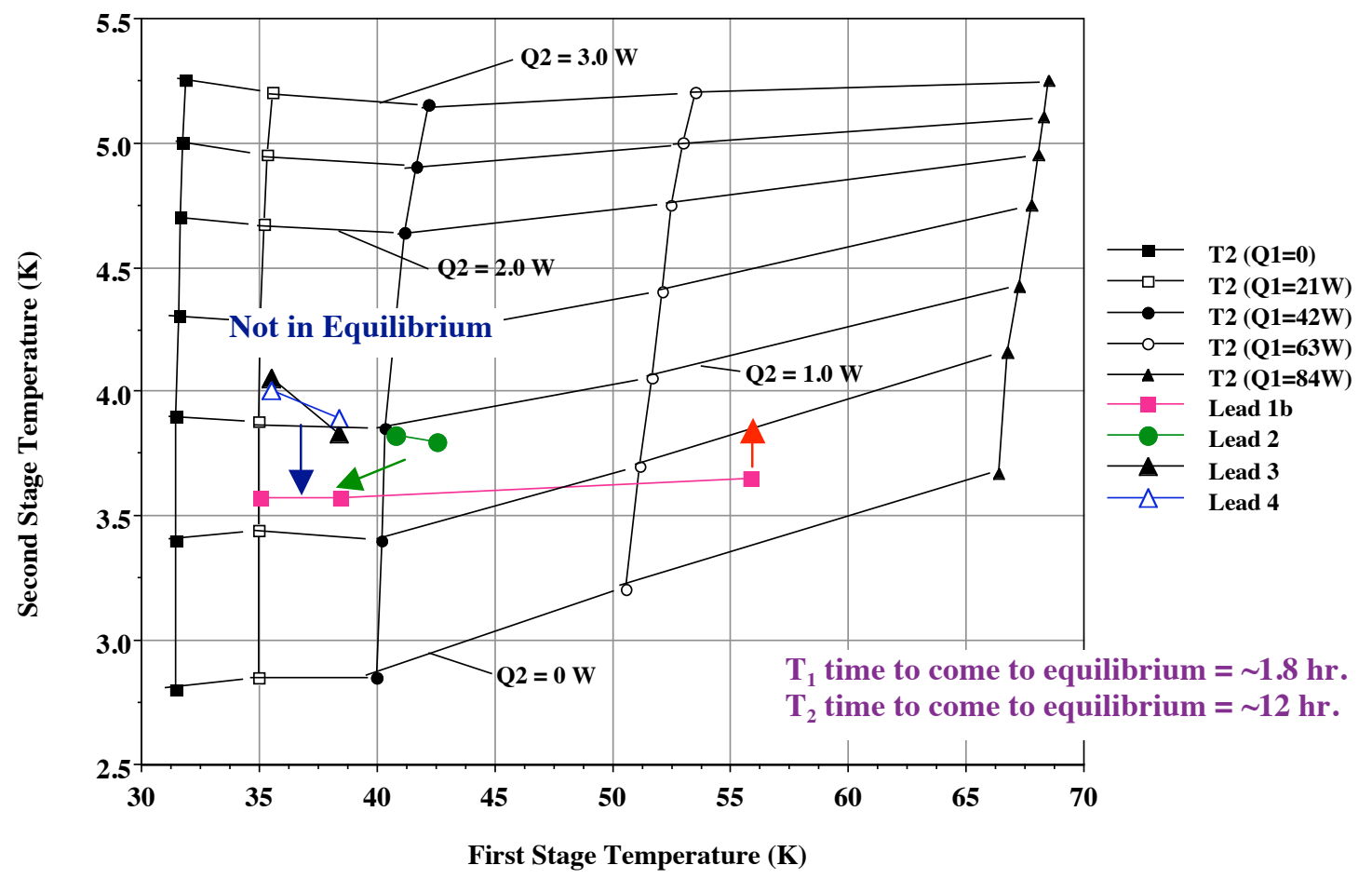

Figure 19. The Performance of Four Pairs Copper Leads with a Design IL/A $=3.3 \times 10^{6} \mathrm{~A} \mathrm{~m}^{-1}($ Lead $1 \mathrm{~b})$ plotted on the Operating Diagram for a Typical PT415 Cooler (see Figure 2)

The effect of not allowing the cooler first-stage and second-stage to come to equilibrium is shown in Figure 19. With lead $1 \mathrm{~b}$, it is clear that both stages came to equilibrium before the start of the test. The last point on the lead 1b plot probably wasn't at equilibrium on the second stage. The red arrow suggests that the second stage temperature should be higher. In the cases where leads 3 and 4 were tested the first stage of the cooler was probably close equilibrium at the start of the test. It is likely that the first stage was at near equilibrium when the leads were powered to $275 \mathrm{~A}$ and held for an hour and a half. It is clear from Figure 19, that the second stage of the cooler was not in equilibrium for leads 3 and 4 . The test of the leads commenced a couple of hours after it was apparent that re-condensation was occurring in the experiment. In both the cases where leads 3 and 4 were tested, the data takers should have waited another eight to ten hours before taking the data. 
The case where lead 2 was tested wasn't in equilibrium for either stage of the cooler. The data takers waited until the cooler was re-condensing, but the copper plate and the shield had not been cooled down fully. In the case of lead 2, the cooler is still cooling down the shield and the copper plate while re-condensing helium.

\section{The Results of Voltage Drop Measurements}

During some of the lead tests, voltage drop measurements were taken to show the voltage drops across the copper leads, the HTS leads, and all of the splices while the circuit is being powered to currents up $275 \mathrm{~A}$. This permits one to estimate the $\mathrm{I}^{2} \mathrm{R}$ heat flow to the cooler first-stage due to the copper leads and the $\mathrm{I}^{2} \mathrm{R}$ heat flow to the cooler second-stage from the HTS leads and splices. (See Figure 4 for the voltage taps.)

Measurements of temperatures and voltage drops were also taken as a function of time and as a function of added heat to the copper plate. Added heat to the copper plate changes the temperature profile in the copper leads. The change of temperature can cause changes in the voltage drop between voltage taps.

Table 5 shows the voltage drops and $\mathrm{I}^{2} \mathrm{R}$ heating for each lead in the copper lead pair $1 \mathrm{a}\left(\mathrm{IL} / \mathrm{A}=5.2 \times 10^{6} \mathrm{~A} \mathrm{~m}^{-1}\right.$ ) as a function of the current. Table 5 also shows the $\mathrm{I}^{2} \mathrm{R}$ heating as a function of current for the leads in lead pair 1a. It was clear that the resistances and $\mathrm{I}^{2} \mathrm{R}$ heating changed with time.

Table 5. The Measured Voltage Drops across the Copper Leads 1a as a Function of Lead Current

\begin{tabular}{ccccc}
\hline \hline \multirow{2}{*}{$\begin{array}{c}\text { Lead Current } \\
(\mathbf{A})\end{array}$} & \multicolumn{2}{c}{ Copper Lead 1 } & \multicolumn{2}{c}{ Copper Lead 2 (V2-V4) } \\
& $\begin{array}{c}\text { V1-V3 } \\
(\mathbf{m V})\end{array}$ & $\begin{array}{c}\mathbf{I}^{\mathbf{2}} \mathbf{R} \text { Heat } \\
(\mathbf{W})\end{array}$ & $\begin{array}{c}\text { V2-V4 } \\
(\mathbf{m V})\end{array}$ & $\begin{array}{c}\mathbf{I}^{\mathbf{1}} \mathbf{R} \text { Heat } \\
(\mathbf{W})\end{array}$ \\
\hline 0 & 0.0115 & $-0-$ & 0.0081 & $-0-$ \\
10 & 6.450 & 0.065 & 4.736 & 0.047 \\
100 & 65.16 & 6.516 & 47.36 & 4.736 \\
275 & 136.9 & 37.65 & 54.8 & 15.07 \\
$275+2 \mathrm{hrs}$ & 110.8 & 30.47 & 97.6 & 26.84 \\
\hline \hline
\end{tabular}

In Table 5, it is clear that the $\mathrm{I}^{2} \mathrm{R}$ heating in copper leads $1 \mathrm{a}$ was excessive at $275 \mathrm{~A}$. From the voltage drops in the leads in lead pair 1a, it is clear that the lead IL/A was too high. As the current increased from $100 \mathrm{~A}$ to $275 \mathrm{~A}$, the heating in the two leads became more unbalanced. The reason for this is not understood. As the copper leads sat at a current of $275 \mathrm{~A}$, the voltage drop and $\mathrm{I}^{2} \mathrm{R}$ heating became more balanced between the two leads. Perhaps lead number 2 was touching the copper plate, which caused a lower initial resistance. The resistive heating is greater than the heat going to the cooler firststage (see Table 4). This means the upper end of the leads is above room temperature.

Table 6 shows the measured voltage drop (after correction for the $\Delta \mathrm{V}$ at $\mathrm{I}=0$ ) across adjacent taps as a function of current in lead pair $1 \mathrm{~b}\left(\mathrm{IL} / \mathrm{A}=3.3 \times 10^{6} \mathrm{~A} \mathrm{~m}^{-1}\right.$ ). Table 7 shows the calculated resistance between the voltage taps from the voltage drop data in Table 6. Table 8 shows the resistive heating as a function of current as the current is going down. The data in Table 8 was created by multiplying the voltage drops in Table 6 by the current in the conductor. 
Table 6. The Measured Voltage Drops across Various Taps as a Function of Lead Current for Leads $1 \mathrm{~b}$

\begin{tabular}{ccccccccc}
\hline \hline & \multicolumn{8}{c}{ Voltage Drop between Taps (mV) } \\
I (A) & $\mathbf{2 7 5}$ & $\mathbf{2 5 0}$ & $\mathbf{2 0 0}$ & $\mathbf{1 5 0}$ & $\mathbf{1 0 0}$ & $\mathbf{5 0}$ & $\mathbf{1 0}$ & \\
\cline { 1 - 7 } V1-3 & 40.8533 & 36.5531 & 26.9165 & 19.2251 & 11.8872 & 5.4791 & 1.0237 & Cu 2 \\
V4-2 & 39.8113 & 34.9731 & 26.5472 & 18.3207 & 11.4191 & 5.3288 & 1.0112 & Cu 1 \\
V3-5 & 0.2049 & 0.1814 & 0.1327 & 0.0962 & 0.0618 & 0.0300 & 0.0070 & HTS 2 \\
V6-4 & 0.1623 & 0.1353 & 0.1002 & 0.0662 & 0.0390 & 0.0165 & 0.0020 & HTS 1 \\
V5-7 & 0.0095 & 0.0064 & 0.0032 & 0.0011 & -0.0012 & -0.0003 & 0.0002 & \\
V7-9 & -0.0035 & -0.0034 & -0.0030 & -0.0032 & -0.0024 & -0.0025 & -0.0023 & \\
V9-10 & -0.0044 & -0.0049 & -0.0026 & -0.0009 & -0.0014 & 0.0002 & 0.0004 & \\
V8-6 & 0.0156 & 0.0122 & 0.0065 & 0.0033 & 0.0016 & 0.0008 & 0.0001 & \\
V10-8 & 0.0104 & 0.0057 & 0.0048 & 0.0031 & 0.0025 & 0.0028 & 0.0005 & \\
\hline \hline
\end{tabular}

Table 7. The Calculated Resistance across Various Taps as a Function of Lead Current for Leads $1 \mathrm{~b}$

\begin{tabular}{|c|c|c|c|c|c|c|c|c|}
\hline \multirow[b]{2}{*}{ I (A) } & \multicolumn{7}{|c|}{ Resistance between Taps $(\mu \Omega)$} & \multirow[b]{3}{*}{$\mathrm{Cu} 2$} \\
\hline & 275 & 250 & 200 & 150 & 100 & 50 & 10 & \\
\hline $\mathrm{V} 1-3$ & 148.557 & 146.212 & 134.583 & 128.167 & 118.872 & 109.582 & 102.370 & \\
\hline V4-2 & 144.768 & 139.892 & 132.736 & 122.138 & 114.191 & 106.576 & 101.120 & Cu 1 \\
\hline V3-5 & 0.745 & 0.726 & 0.664 & 0.641 & 0.618 & 0.600 & 0.700 & HTS 2 \\
\hline V6-4 & 0.590 & 0.541 & 0.501 & 0.441 & 0.390 & 0.330 & 0.200 & HTS 1 \\
\hline V5-7 & 0.035 & 0.026 & 0.016 & 0.007 & -0.012 & -0.006 & 0.020 & \\
\hline V7-9 & -0.013 & -0.014 & -0.015 & -0.021 & -0.024 & -0.050 & -0.230 & \\
\hline V9-10 & -0.016 & -0.020 & -0.013 & -0.006 & -0.014 & 0.004 & 0.040 & \\
\hline V8-6 & 0.057 & 0.049 & 0.033 & 0.022 & 0.016 & 0.016 & 0.010 & \\
\hline \multirow[t]{3}{*}{ V10-8 } & 0.038 & 0.023 & 0.024 & 0.021 & 0.025 & 0.056 & 0.050 & \\
\hline & 0.100 & 0.064 & 0.044 & 0.023 & -0.009 & 0.020 & -0.110 & Misc \\
\hline & 294.761 & 287.436 & 268.528 & 251.411 & 234.062 & 217.108 & 204.280 & Total \\
\hline
\end{tabular}

Table 8. The Calculated $I^{2} \mathrm{R}$ Heating across Various Taps as a Function of Lead Current for Leads $1 \mathrm{~b}$

\begin{tabular}{|c|c|c|c|c|c|c|c|}
\hline \multirow[b]{2}{*}{$\mathbf{I}(\mathbf{A})$} & \multicolumn{7}{|c|}{ Resistive Heating between Taps (mW) } \\
\hline & 275 & 250 & 200 & 150 & 100 & 50 & 10 \\
\hline V1-3 & 11234.7 & 10052.1 & 7402.0 & 5286.9 & 3269.0 & 1506.8 & 281.5 \\
\hline V4-2 & 10948.1 & 9617.6 & 7300.5 & 5038.2 & 3140.3 & 1465.4 & 278.1 \\
\hline V3-5 & 56.3 & 49.9 & 36.5 & 26.5 & 17.0 & 8.3 & 1.9 \\
\hline V6-4 & 44.6 & 37.2 & 27.6 & 18.2 & 10.7 & 4.5 & 0.6 \\
\hline V5-7 & 2.6 & 1.8 & 0.9 & 0.3 & 0.3 & 0.1 & 0.1 \\
\hline V7-9 & 1.0 & 0.9 & 0.8 & 0.9 & 0.7 & 0.7 & 0.6 \\
\hline V9-10 & 1.2 & 1.3 & 0.7 & 0.2 & 0.4 & 0.1 & 0.1 \\
\hline V8-6 & 4.3 & 3.4 & 1.8 & 0.9 & 0.4 & 0.2 & 0.0 \\
\hline \multirow[t]{3}{*}{ V10-8 } & 2.9 & 1.6 & 1.3 & 0.9 & 0.7 & 0.8 & 0.1 \\
\hline & 11.9 & 9.0 & 5.5 & 3.2 & 2.5 & 1.8 & 1.0 \\
\hline & 22295.7 & 19765.8 & 14772.1 & 10372.9 & 6439.5 & 2986.8 & 563.0 \\
\hline
\end{tabular}

From Table 7 one can see that the resistance of the copper leads goes down as the current goes down. The copper leads are being cooled by the cooler first stage, which changes the distribution of the resistance in the copper leads. 
The resistance (Table 7) of the HTS leads goes down with current in the same was as the copper lead resistance goes down. This indicates that the voltage drop being in measured in the HTS leads is likely due to copper attached to the upper part of the leads that is between the voltage taps and the HTS leads. From Table 8, one can see that the resistive heating in the copper leads is much lower for leads 1b. From Table 8 one can see that there is resistive heating between the voltage taps that include the HTS leads. In the operating temperature range for the HTS leads, they should have virtually no resistance or resistive heating. The resistive heating seen in Table 8 for the HTS leads is probably due to the copper between the voltage taps. The heating that is attributed to the HTS leads is taken up by the cooler first stage. For leads $1 \mathrm{~b}$, the heat to the cooler first stage at $275 \mathrm{~A}$ (see Table 4) is greater than the total resistive heating. This means that the temperature of the upper end of the copper lead is below room temperature.

The resistances of the splices between superconductors vary all over the place. These errors in the measurement voltage could be due to noise in the system. In any event, the resistance data for the splices suggests splice resistances in the tens of n-ohm range [28], [29], which very difficult to measure. The volt meters used for the splice resistance tests at Berkeley are much better than the volt meter used in the vendors shop. It is expected that there is a lot of noise in the system that is not present in the system used to measure LTS conductor splice resistance at Berkeley. The expected resistance for 100-mm long splices between the LTS superconductors used in the lead cooler experiment is in the range from 10 to 30 n-ohms [29].

In order to understand the behavior of the leads with time and the time constants involved in the process. The leads were run at $275 \mathrm{~A}$ for a period of time. $30 \mathrm{~W}$ of heat was added by a heater attached to the copper plate. This heater was located between the copper ring and the thermal intercepts to the copper plate from the copper leads. Since the thermal drop between the top of the HTS leads and the first-stage cold head is dominated by the temperature drop in the copper plate (see Table 3), the extra heat applied to the copper plate near the thermal intercept point for the copper leads increases the temperature drop between the top of the HTS leads (sensors T8 and T9) and the firststage cold head T5. This is well illustrated in Table 9. The 30-W heater was turned on a 3:31 PM just after the first set of temperatures (column 2 of Table 9) was taken. The heater was turned off at 5:32 PM just after the temperature data in column 4 of table 9 was taken. The current was shut off at 6:01 PM.

Table 9. Measured Temperature as a Function of Added Heat Load and Current in the Copper leads ( $\mathrm{T} 1$ is the He tank temperature and $\mathrm{T} 2$ is the $2^{\text {nd }}$-stage Temperature. T5 is the $1^{\text {st }}$ stage temperature; T6 is the copper plate temperature and, temperature T8, and T9 are the HTS lead temperatures.)

\begin{tabular}{ccccccc}
\hline \hline Time & $3: 30 \mathrm{PM}$ & $5: 00 \mathrm{PM}$ & $5: 30 \mathrm{PM}$ & $5: 45 \mathrm{PM}$ & $6: 00 \mathrm{PM}$ & $6: 45 \mathrm{PM}$ \\
$\mathrm{I}(\mathrm{A})$ & 275 & 275 & 275 & 275 & 275 & 0 \\
$\mathrm{Q}_{\mathrm{A}}(\mathrm{W})$ & 0 & 30 & 30 & 0 & 0 & 0 \\
\hline $\mathrm{T} 1$ & 4.06 & 4.08 & 4.10 & 4.10 & 4.09 & 4.05 \\
$\mathrm{~T} 2$ & $\sim 3.96$ & $\sim 3.96$ & $\sim 3.98$ & $\sim 3.99$ & $\sim 3.98$ & $\sim 3.95$ \\
$\mathrm{~T} 5$ & 38.4 & 55.1 & 55.9 & 49.5 & 46.7 & 38.1 \\
$\mathrm{~T} 6$ & 52.2 & 72.3 & 73.4 & 68.4 & 63.7 & 48.9 \\
$\mathrm{~T} 8$ & 51.6 & 72.8 & 73.8 & 68.9 & 64.2 & 48.1 \\
$\mathrm{~T} 9$ & 52.7 & 73.8 & 75.1 & 69.4 & 65.2 & 48.9 \\
\hline \hline
\end{tabular}


Table 9 illustrates that the time constants for thermal changes at the first stage are quite long. In order for the system to come to equilibrium, one would have to wait at least 4 hours between temperature changes. The thermal time constants for atage- 2 are longer. One must allow about 12 hours for the temperature on the second stage to come to equilibrium.

Tables 10 through 12 are similar to Tables 6 through 8 except that these tables apply for the cases given in Table 9. Table 10 shows the voltage drops across the taps for the $1 \mathrm{~b}$ leads. Table 11 shows the resistance between the taps, and Table 12 shows the resistive heating between the taps for the cases shown in Table 9 .

Table 10. The Voltage Drops across Various Taps as a Function of Lead Current and Added Heat to the Copper Plate for Leads $1 \mathrm{~b}$ (See Table 9 for the temperatures)

\begin{tabular}{|c|c|c|c|c|c|}
\hline & \multicolumn{5}{|c|}{ "Voltage Drops between Taps (mV) } \\
\hline Time & 3:30 PM & 5:00 PM & $5: 30 \mathrm{PM}$ & $5: 45 \mathrm{PM}$ & 6:00 PM \\
\hline $\mathrm{I}(\mathrm{A})$ & 275 & 275 & 275 & 275 & 275 \\
\hline $\mathrm{Q}_{\mathrm{A}}(\mathrm{W})$ & 0 & 30 & 30 & 0 & 0 \\
\hline V1-3 & 36.9866 & 42.7362 & 43.0639 & 42.2591 & 40.8533 \\
\hline V4-2 & 35.8877 & 41.7213 & 41.9898 & 41.0111 & 39.8113 \\
\hline V3-5 & 0.1368 & 0.2867 & 0.2995 & 0.2538 & 0.2049 \\
\hline V6-4 & 0.1264 & 0.2041 & 0.2085 & 0.1821 & 0.1623 \\
\hline V5-7 & 0.0044 & 0.0071 & 0.0100 & 0.0100 & 0.0095 \\
\hline V7-9 & 0.0328 & -0.0284 & -0.0361 & -0.0146 & -0.0035 \\
\hline V9-10 & -0.0038 & -0.0043 & -0.0032 & -0.0042 & -0.0044 \\
\hline V8-6 & 0.0119 & 0.0200 & 0.0180 & 0.0180 & 0.0156 \\
\hline V10-8 & -0.0258 & 0.0373 & 0.0396 & 0.0188 & 0.0104 \\
\hline
\end{tabular}

Table 11. The Calculated Resistances between Various Taps as a Function of Lead Current and Added Heat to the Copper Plate for Leads $1 b$ (See Table 9 for the temperatures)

\begin{tabular}{|c|c|c|c|c|c|}
\hline & \multicolumn{5}{|c|}{ Calculated Resistance between Taps $(\mu \Omega)$} \\
\hline Time & 3:30 PM & 5:00 PM & $5: 30 \mathrm{PM}$ & $5: 45$ PM & 6:00 PM \\
\hline $\mathrm{I}(\mathrm{A})$ & 275 & 275 & 275 & 275 & 275 \\
\hline $\mathrm{Q}_{\mathrm{A}}(\mathrm{W})$ & 0 & 30 & 30 & 0 & 0 \\
\hline V1-3 & 134.497 & 155.404 & 156.596 & 153.669 & 148.557 \\
\hline V4-2 & 130.501 & 151.714 & 152.690 & 149.131 & 144.768 \\
\hline V3-5 & 0.497 & 1.043 & 1.089 & 0.923 & 0.745 \\
\hline V6-4 & 0.460 & 0.742 & 0.758 & 0.662 & 0.590 \\
\hline V5-7 & 0.016 & 0.026 & 0.036 & 0.036 & 0.035 \\
\hline V7-9 & 0.119 & -0.103 & -0.131 & -0.053 & -0.013 \\
\hline V9-10 & -0.014 & -0.016 & -0.012 & -0.015 & -0.016 \\
\hline V8-6 & 0.043 & 0.073 & 0.065 & 0.065 & 0.057 \\
\hline \multirow[t]{3}{*}{ V10-8 } & -0.094 & 0.136 & 0.144 & 0.068 & 0.038 \\
\hline & 0.071 & 0.115 & 0.103 & 0.102 & 0.100 \\
\hline & 266.025 & 309.018 & 311.236 & 304.488 & 294.761 \\
\hline
\end{tabular}


Table 12. The Calculated Resistive Heating between Various Taps as a Function of Lead Current and Added Heat to the Copper Plate for Leads $1 b$ (See Table 9 for the temperatures)

\begin{tabular}{ccccccc}
\hline & \multicolumn{7}{c}{ Calculated Resistive Heating between Taps $(\mathbf{m W})$} & \\
Time & $3: 30 \mathrm{PM}$ & $5: 00 \mathrm{PM}$ & $5: 30 \mathrm{PM}$ & $5: 45 \mathrm{PM}$ & $6: 00 \mathrm{PM}$ & \\
I (A) & 275 & 275 & 275 & 275 & 275 & \\
$\mathrm{Q}_{\mathrm{A}}(\mathrm{W})$ & 0 & 30 & 30 & 0 & 0 & \\
\hline V1-3 & 10171.3 & 11752.5 & 11842.6 & 11621.3 & 11234.7 & Cu 2 \\
V4-2 & 9869.1 & 11473.4 & 11547.2 & 11278.1 & 10948.1 & Cu 1 \\
V3-5 & 37.6 & 78.8 & 82.4 & 69.8 & 56.3 & HTS 2 \\
V6-4 & 34.8 & 56.1 & 57.3 & 50.1 & 44.6 & HTS 1 \\
V5-7 & 1.2 & 2.0 & 2.8 & 2.8 & 2.6 & \\
V7-9 & 9.0 & 7.8 & 9.9 & 4.0 & 1.0 & \\
V9-10 & 1.0 & 1.2 & 0.9 & 1.2 & 1.2 & \\
V8-6 & 3.3 & 5.5 & 5.0 & 5.0 & 4.3 & \\
V10-8 & 7.1 & 10.3 & 10.9 & 5.2 & 2.9 & \\
\cline { 1 - 5 } & 21.6 & 26.7 & 29.4 & 18.0 & 11.9 & Misc \\
& 20134.5 & 23387.5 & 23558.9 & 23037.2 & 22295.7 & Total
\end{tabular}

There were a number of negative voltage drops measured between some of the voltage tabs. These voltage measurements may represents errors introduced by dissimilar metals and ground loops. The quality of the voltage measurements seems to be OK at the level of 0.5 to $1.0 \mu \mathrm{V}$. Below that level, error appears to be creeping into the measurements. Some of the error may be coming from the power supply, but there are a number of other sources of error. The voltage data for tap V7-9 and V8-10 shows a change of sign with time. There may also be a temperature effect that appears to be related to the heat added to the copper plate. When the current is shut off the voltages measured by these taps are lower. The resistances between taps V7-9 and V8-10 are probably not real either.

On average the temperature of the copper is warmer when heat is added to the copper plate. As a result, the copper lead temperature is warmer. As a result, the lead resistance and resistive heating is increased. From Table 12 we can see that the resistive heating of all of the LTS splices is not likely to exceed $30 \mathrm{~mW}$. The resistive heating between V3-5 and V6-4 is most likely due to copper that is in contact with the top of the HTS and the copper plate. The heating between tap V3-5 is higher than between taps V6-4, when there is $30 \mathrm{~W}$ of added heat flowing into the copper plate due to the heater. The extra heat seems to affect the heating across HTS lead 2 more than it does across HTS lead 1. The author doesn't believe that this heating is occurring in the HTS leads, even when the temperature of the top of the leads is in the range from 73 to $75 \mathrm{~K}$, but resistive heating in the HTS leads can't be ruled out. If there is HTS lead resistance heating, it doesn't appear to be running away.

Leads $1 \mathrm{~b}$ seem to be more uniform in their properties than leads 1a. Unfortunately voltage drop measurements were not taken with leads 2,3 and 4. The test plan was not followed, and as a result, we don't know how the resistance varies between several identical leads. 


\section{Some Concluding Comments, "What was learned from these tests?"}

The cooler lead test did a great deal to increase our understanding of what happened with the spectrometer solenoids during the tests of the last two years [34], [35]. From the results of the latest spectrometer solenoid test [35] and the cooler-lead tests, we can improve the operating performance of the coupling magnet [36]. Knowing how the copper and HTS leads behave while the system was connected to a PT415 cooler greatly enhances our understanding of how the coolers and the magnets behave as a system [18], [21], [35]. The cooler and lead test satisfied the following requirements:

1) The leads in magnet $2 \mathrm{~A}$ were not operating at their optimum IL/A. We found that much better lead performance was achieved at IL/A close to that calculated by ICST for the coupling magnet [16].

2) The experiment measured the voltage drops across the copper leads, the HTS leads and the various splices in the system. One could correlate the measured resistive heating in the copper leads with the measured first-stage refrigeration.

3) Long time constants for coming to equilibrium were measured and compared to a model for the time constants that can be applied to the MICE magnets. The firststage time constant was long, but time constant for the cooler second stage was much longer. As a result, of not waiting long enough, important data was lost.

4) The temperature drop between the top of the HTS leads and the cooler first stage was measured directly. The largest portion of the temperature drop is across the copper plate between the leads and the ring that the cooler seats into.

5) The effect of heat being added to the copper plate was clearly demonstrated in terms of its affect on the temperature drop and its affect on the cooler first-stage temperature. Limit heat flow from all sources not just the copper leads.

6) The importance of making a test plan and sticking to that test plan was clearly demonstrated.

The lessons learned from the cooler and lead experiment can result in a better design and better execution of the design all three MICE magnets. Controlling the heat flow into the cooler first stage and minimizing the temperature drops from the tops of the HTS leads to the cooler first stages are important for the coupling and focusing magnet because of the high magnetic fields generated by these magnets.

Leads $1 \mathrm{~b}$ (also 2, 3, and 4 which have a similar IL/A) were much better the leads 1a that were used in magnet 1 and magnet $2 \mathrm{~A}$. A pair of leads $1 \mathrm{~b}$ had a no current heat leak of $\sim 16 \mathrm{~W}$. The performance with $275 \mathrm{~A}$ in the leads was $\sim 31 \mathrm{~W}$. Leads $1 \mathrm{a}$ had a no current heat leak of $\sim 8 \mathrm{~W}$ per pair, while the heat leak with $275 \mathrm{~A}$ was $\sim 42 \mathrm{~W}$ per pair. There was heating of leads $1 \mathrm{a}$ at the room temperature end, which is indicative of an IL/A that is too high. The performance of leads $1 \mathrm{~b}$ is close to optimum, but the IL/A for these leads may be a little low, because there is heat flow into the leads at the room temperature end, when they operate at $275 \mathrm{~A}$. It is difficult to predict the optimum IL/A for a pair of leads without knowing the properties of the material going into the leads. The residual resistance ratio (RRR) of the welding cable used to fabricate the leads is not known. In general, the higher the RRR the higher the optimum IL/A must be. It may be better to fabricate leads with a material that has a low RRR that is known. 
The voltage drops across the copper leads were different for each lead in the pair. The voltage drops across the leads varied with time. This change in voltage drop and resistive heating with time is indicative of the time needed for the system to come to equilibrium. It is believed that most of the voltage drop across the HTS leads is actually a voltage drop across some copper at the warm end of the HTS leads. Therefore, most of the resistive heating in HTS leads will be taken to the first-stage of the cooler. Resistive heating in the HTS leads themselves can't be completely ruled out, particularly if the upper end temperature is above $70 \mathrm{~K}$. If there is resistive heating in the HTS leads, it appears that the leads are not running away. Heating that actually occurs in the HTS leads will be conducted to the helium bath and the cooler second-stage.

The time constants for cooler temperature changes are long. The first-stage temperature change time constant is determined by the copper mass in direct contact with the cooler first stage and the number of coolers removing the heat. The mass of the shield should also be considered. The time constant for temperature changes at the cooler second-stage is determined by the mass of liquid helium in the contact with the cold mass and the number of coolers removing the heat. The mass of the $4 \mathrm{~K}$ metal in the cold mass has only a small effect on the time constant. The MICE spectrometer solenoid, which has about $22 \mathrm{~kg}$ of helium in the tank and three $4 \mathrm{~K}$ coolers, requires $\sim 40$ hours to come to equilibrium (4 to 5 time constants). The MICE coupling magnet, which has about $2.5 \mathrm{~kg}$ of helium in contact with two $4 \mathrm{~K}$ coolers, will require $\sim 7$ hours to come to equilibrium. Similar calculations can be done for the MICE focusing magnets.

The temperature drop between the tops of the HTS leads and the cooler first-stage must be made as low as possible for the MICE coupling and focusing magnets. The temperature drop is less important for the spectrometer solenoids, because a single stage cooler can be used and the HTS leads have more temperature margin. The process of delivering the heat from the copper leads to the cooler cold heads must be examined. The following steps must be taken to reduce the total temperature drop from the HTS lead tops to the cooler first stage: 1) Design the copper leads for the current you need not the maximum power supply current. 2) The joint between the drop in cooler cold head and the copper plate must have as large an area as possible and the tapered joint on the cold head must fit snugly against the copper ring that transports the heat across the joint in order to minimize $\Delta \mathrm{T}_{1}$ across the joint. 3) Minimize other sources of heat from the shields and intercepts to minimize $\Delta \mathrm{T}_{2}$. 4) The receiving ring must be welded to the copper plate in order to minimize $\Delta \mathrm{T}_{2}$. The ring should allow the heat to be collected from the copper plate over a broad area. 5) The heat from the lead thermal intercepts into the copper plate must be spread over a broad area in order to minimize the temperature drop $\Delta T_{2}$. 6) The copper plate must be made thick enough to carry the heat (including shield heat) and minimize $\Delta \mathrm{T}_{2}$. Note: The combination of steps 3 through 6 will minimize the temperature drop across the copper plate $\Delta \mathrm{T}_{2}$. 7) The intercept that carries the heat from the copper leads to the copper plate must have a large area and thin electrical insulation in order to minimize the intercept temperature drop $\Delta \mathrm{T}_{3}$.

Finally, the copper plate must have enough mass to provide cooling to the tops of HTS leads while the magnet is discharged during a power failure. If the copper plate doesn't have enough mass to provide the cooling for the HTS leads, this cooling must be provided by boil-off gas from the magnet [17]. 


\section{Acknowledgment}

This work was supported by the Office of Science of the US Department of Energy under DOE contract DE-AC-02-05CH11231.

\section{References}

[1] G. Gregoire, G. Ryckewaert, L. Chevalier, et al, "MICE and International Muon Ionization Experiment Technical Reference Document," http://www.mice.iit.edu, (2001).

[2] M. A. Green, "Cooling the MICE Magnets using Small Cryogenic Coolers," MICE Note 109, http://www.mice.iit.edu, 10 September 2004.

[3] S. T. Wang, R. Wahrer, C. Taylor, et al, "The Design and Construction of the MICE Spectrometer Solenoids," IEEE Transactions on Applied Superconductivity 19, No. 3 p 1348, (2009).

[4] D. E. Baynham, T. W. Bradshaw, J. H. Cobb, et al, "Progress on the Design and Fabrication of the MICE Focusing Magnets," to be published in IEEE Transactions on Applied Superconductivity 20, No. 3, p 308, (2010).

[5] D. Li, M. A. Green, S. P. Virostek, and M. S. Zisman, "Progress of the RF coupling Module for the MICE Channel," Proceedings of 2005 Particle Accelerator Conference Knoxville TN, p 2869, (2005).

[6] L. Wang, H. Pan, X. K. Liu, et al, "Design and Construction of Test Coils for MICE Coupling Solenoid Magnet,", IEEE Transactions on Applied Superconductivity 19, No. 3 p 1340, (2009).

[7] Cryomech Incorporated, Data concerning the PT415 Two Stage Pulse Tube cooler, 113 Falso Drive, Syracuse NY 13211, USA, http://www.cryomech.com.

[8] M. A. Green and H. Witte, "The Use of Small Coolers in a Magnetic Field," Advances in Cryogenic Engineering 53, p 1299, AIP Press, Melville NY (2008).

[9] M. A. Green, S. Q. Yang, J. H. Cobb, et al, "The Effect of Magnetic Field on the Position of the HTS Leads and the Cooler in the Service Tower of the MICE Focusing Magnet," IEEE Transactions on Applied Superconductivity 18, No. 2, p 1447 (2008).

[10] M. A. Green and H. Witte, "Using High Temperature Superconducting Leads in a Magnetic Field," Advances in Cryogenic Engineering 53, p 1251, AIP Press, Melville NY (2008).

[11] M. A. Green and S. Q. Yang, "Heat Transfer into and within the $4.4 \mathrm{~K}$ Region and the $40 \mathrm{~K}$ Shields of the MICE Focusing and Coupling Magnets," MICE Note 101, http://www.mice.iit.edu, April 2004,

[12] M. A. Green, "The Integration of Liquid Cryogen Cooling and Cryocoolers with Superconducting Electronics Systems," Superconducting Science and Technology 16, No. 12, p 1349, (2003).

[13] M. A. Green, D. R. Dietderich, S. Marks, et al, "Design Issues for Cryogenic Cooling of Short Period Superconducting Undulators," Advances in Cryogenic Engineering 49, p 783, (2004).

[14] M. A. Green, "How the Performance of a Superconducting Magnet is affected by the Connection between a Small Cooler and the Magnet," IEEE Transactions on Applied Superconductivity 16, No. 1, p 1330, (2006).

[15] M. N. Wilson, Superconducting Magnets, Chapter 11, Oxford University Press, Oxford UK, (1983)

[16] L. Wang, L. K. Li, H. Wu, et al, "Design of Current Leads for the MICE Coupling Magnet," Proceedings International Conference of Cryogenics and Refrigeration 22, Shanghai China, p 347, MICE Note 219, http://www.mice.iit.edu, April 2008

[17] M. A. Green, H. Wu, L. Wang, et al, "AC Losses in the MICE Magnets is this a Curse or a Blessing.” MICE Note 195, http://www.mice.iit.edu, January 2008. 
[18] M. A. Green and S. T. Wang, "Tests of Four PT-415 Coolers Installed in the Drop-in Mode," co-authored with S. T. Wang, Proceedings ICEC-22, p 859, Seoul Korea, (2009)

[19] M. A. Green, S. P. Virostek, D. Li, et al, "Progress on the Superconducting Magnets for the MICE Cooling Channel," to be published in Journal of Physics Conference Series (2009) MICE, Note 274, http://www.mice.iit.edu, September 2009.

[20] M. A. Green, "The Liquefaction of Hydrogen and Helium using Small Coolers," LBNL62459, MICE Note 161, http://www.mice.iit.edu, February 2007

[21] M. A. Green, Re-condensation and Liquefaction of Helium and Hydrogen using Coolers," to be published in Advances in Cryogenic Engineering 55, p 703, AIP Press, Melville NY (2010). MICE Note 239, http://www.mice.iit.edu, July 2009

[22] S. P. Virostek, and M. A. Green, "The Results of Tests of the MICE Spectrometer Solenoids," to be published in IEEE Transactions on Applied Superconductivity 20, No. 3 , p 377, (2010), MICE Note 279, http://www.mice.iit.edu, October 2009

[23] Y. S. Choi, T. A. Painter, D. L. Kim, et al, "Helium-Liquefaction by Cryocooler for HighField Magnets Cooling, " Proceedings of the International Cryocooler Conference (2006)

[24] A. M. Kadin, R. J. Webber, and D. Gupta, "Current Leads and Optimized Thermal Packaging for Superconducting Systems on Multistage Cryocoolers," IEEE Transactions on Applied Superconductivity 17, No. 2, p 915, (2007)

[25] M. A. Green, L. X. Jia, L. J. Addessi, J. R. Cullen Jr., A. J. Esper and R. E. Meier, "A Design Method for Multi-tube Gas Cooled Electrical Leads for the g-2 Superconducting Magnets," co-authored with Advances in Cryogenic Engineering 41, p 573, Plenum Press, New York (1996)

[26] M. A. Green and H. Witte, "Quench Protection and Magnet Power Supply Requirements For the MICE Focusing and Coupling Magnets," MICE Note 114, http://www.mice.iit.edu, LBNL-57580, (June 2005)

[27] R. G. Smits, et al, "Gas-Cooled Electrical Leads for Use on Forced Cooled Superconducting Magnets", Advances in Cryogenic Engineering 27, p 169, Plenum Press, New York, (1981)

[28] M. A. Green, D. Dietderich, H. C. Higley et al, "The Calculated and measured Resistance for Splices between Conductors in a MICE Superconducting Coil," LBNL-2553E, MICE Note 238, http://www.mice.iit.edu, (March 2009)

[29] F. Y. Xu, H. Pan, H. Wu. et al, "Measurement of Resistance and Strength of Conductor Splices in the MICE Coupling Magnets," Advances in Cryogenic Engineering 55, p 1434, AIP Press, Melville NY, (2010)

[30] V. D Arp and R. D. McCarthy, "Thermophysical Properties of Helium-4 from 0.8 to 1500 K with Pressures to 2000 MPa," NIST Technical Note 1334, (1989)

[31] Chao Wang, Cryomech Inc. private communication concerning the connection of a drop in cooler with the shield and lead plate of a cryo-cooled magnet system (2007).

[32] E. D. Marquardt, J. P. Le, R. Radebaugh, "Cryogenic Materials Property Database," presented at the $11^{\text {th }}$ International Cryocooler Conference. 20-22 June 2000, Keystone CO, http:// www.cryogenics.nist.gov/Papers/Cryo Materials.pdf (2000)

[33] V. J. Johnson (ed) WADD Compendium, "Properties of Materials at Low Temperature," Vol. 2 (solids), Pergamon Press, (1961)

[34] S. P. Virostek, M. A. Green, F. Trillaud, and M. S. Zisman, "Fabrication, Testing and Modeling of the MICE Superconducting Spectrometer Solenoids," Proceedings of the 2010 International Particle Accelerator Conference, Kyoto Japan, 23 to 27 May 2010, (2010)

[35] M. A. Green, "What Happened with Spectrometer Magnet 2B," MICE Note 292, http://www.mice.iit.edu, (27 May 2010)

[36] M. A. Green, L. Wang, H. Pan, et al, "Lessons Learned for the MICE Coupling Solenoid from the MICE Spectrometer Solenoid," Proceedings of the 2010 International Particle Accelerator Conference, Kyoto Japan, 23 to 27 May 2010, (2010) 


\section{APPENDIX \\ What we want to Test and the Test Experimental Procedure}

\section{Michael A. Green \\ 11 January 2010}

Before the test we want to do the following. We want to get all of the water out of the helium tank. We want to re-attach temperature sensor 6 to the copper plate in a position that is close to where the lead heat load comes into the plate. The fact that temperature measured at sensor $\mathrm{T} 6$ is $40 \mathrm{~K}$ more than the temperature measured by sensors T5 and T7 suggests that sensor T6 became unglued. It appears that we are measuring the temperature of the wires coming into the sensor T6 not the temperature of the copper plate. We must also repair the vacuum leak in the ceramic seal around the leads or we must replace the ceramic feed through.

We must eliminate the source of the thermal acoustic oscillation observed in the vent line. This may require that G-10 plug with a passage around the plug for flow be inserted in the bottom of the line. Perhaps a cotton or nylon cord down the opening will eliminate the thermal acoustic oscillation. I don't think that the oscillation will go away by changing the cooler operating conditions.

We also want to measure the temperature at the top of each of the 300 A HTS leads. The temperatures could be designated as temperature sensors T3 and T4. We want to know the total temperature drop from the top of the HTS leads to the cooler first stage when the leads are not powered and when the leads are operating at their design current.

Since the thermal conductivity of the material that is in the joint between the copper ring and the cooler first stage varies with temperature we would like to operate this joint over a range of temperatures from $35 \mathrm{~K}$ to about $75 \mathrm{~K}$. Since the thermal conductivity of the Kapton that is in the lead heat intercept varies with temperature we would like to operate this joint over a range of temperatures from $35 \mathrm{~K}$ to about $80 \mathrm{~K}$. In order to understand what happened in Magnet 2, we may want to extend the temperature range by putting up to $80 \mathrm{~W}$ onto the copper plate.

We would like to measure the following during the cooler and lead test:

1) We want to measure the following temperatures: the $2^{\text {nd }}$ stage cold head temperature (currently T1), 2) the temperature of the helium tank (currently T2), 3 ) the temperature of the $1^{\text {st }}$ stage cold head (currently T5), 4) the temperature of the copper ring that is pressed against the $1^{\text {st }}$ stage cold head (currently T7), 5) the temperature of the $1 / 4$ inch thick copper plate close to where the leads are connected (currently T6), 6) the temperature of the top of HTS lead 1 (this could be T3), and 7) the temperature of the top of HTS lead 2 (this could be T4)

2) We want to measure the pressure in the helium tank during all tests. The tank pressure is the best measure of the tank temperature and the first stage temperature that we will have, unless we use fully calibrated Cernox sensors on both the tank and the second stage of the cooler. The pressure coupled with the diodes sensors T1 and T2 will give us a good picture as to what is going on in the $4 \mathrm{~K}$ region.

3) We want to measure the following while there is current flowing in the leads: 1) the voltage drop from $\mathrm{V} 1$ to $\mathrm{V} 3,2$ ) the voltage drop from $\mathrm{V} 2$ to $\mathrm{V} 4,3$ ) the 
voltage drop from $\mathrm{V} 3$ to $\mathrm{V} 5,4)$ the voltage drop from $\mathrm{V} 4$ to $\mathrm{V} 6,5)$ the voltage drop from V5 to V7, 6) the voltage drop from V6 to V8, and 7) the voltage drop from V7 to V8. These voltage drops should be measured at $300 \mathrm{~A}$ (when $300 \mathrm{~A}$ leads are installed), after the system has come to equilibrium. These voltage drops should be measured at $60 \mathrm{~A}$ (when 60 A leads are installed), after the system has come to equilibrium. The voltage drops from V1 to V3 and V2 to V4 alone will tell us if the copper lead design is optimum at the copper lead design current. If the leads are optimum, the voltage drops V1 to V2 and V3 to V4 should be from 45 to $50 \mathrm{mV}$ when the leads carry their design current. If the voltage drop at the design current is greater than $50 \mathrm{mV}$, the IL/A for the total lead package (from the room temperature side of the ceramic to the top of the HTS lead) is too large. If the copper voltage drop is less than $45 \mathrm{mV}$, the IL/A for the copper lead is too small. When the voltage drop down the leads is too small, the heat leak without current will be more than fifty percent of the heat leak when the leads operate at full current. When the experiment is operating correctly with the HTS leads superconducting, all of the other voltage drops should be in the range from 2 to $20-\mu \mathrm{V}$.

4) We want measure the cooler performance with the following heat loads on the $1^{\text {st }}$ and $2^{\text {nd }}$ stages: 1 ) Operate with zero heater heat load on the $1^{\text {st }}$ stage (only the lead heat load) and zero heater heat load on the $2^{\text {nd }}$ stage with no current in the leads. 2) Operate with zero heater heat load on the $1^{\text {st }}$ stage (only the lead heat load) and zero heater heat load on the $2^{\text {nd }}$ stage with the design current in the leads. 3) Repeat steps 1 and 2 with $0.5 \mathrm{~W}$ of heat load into the helium tank. 4) Repeat step 3 with $30 \mathrm{~W}$ of heat applied to the copper plate that is attached to the $1^{\text {st }}$ stage. 5) Repeat step 3 with $60 \mathrm{~W}$ added to the copper plate that is attached to the $1^{\text {st }}$ stage. 6) Repeat steps 1 and 2 with $1.0 \mathrm{~W}$ of heat load into the helium tank. 7) Repeat step 6 with $30 \mathrm{~W}$ of heat applied to the copper plate that is attached to the $1^{\text {st }}$ stage. 8) Repeat step 6 with $60 \mathrm{~W}$ added to the copper plate that is attached to the $1^{\text {st }}$ stage.

The operating procedure for the experiment is to use the cooler to cool down the experiment, so that the first stage reaches a temperature of $50 \mathrm{~K}$ before filling the tank with helium. The cooling of the experiment should be done with the helium space filled with helium a pressure slightly above atmospheric. Ideally one wants to put the helium into the experiment through the tube that contains the wire to the temperature sensor. With helium gas entering the experiment from the top of the cooler, the cool will cool down the tank to $4 \mathrm{~K}$ and make liquid in the tank. This was demonstrated in a previous cooler test. This may not be possible in the experiment as configured, so simply pressurizing the tank will have to do.

The procedure for cooling down the experiment and operating the experiment should be as follows when pair of 300-A leads connect from room temperature to the HTS leads:

1) Pump out the experiment and make sure that the vacuum is good enough to allow the experiment to be turned on. There should be no air leak into the experimental vacuum space. 
2) Pressurize the experiment to a pressure of about 1.1 bar (16.2 psia or $1.5 \mathrm{psig})$. Keep the experiment under this pressure during the cool down of the cooler and the tank.

3) Turn on the cooler and allow the cooler to cool down both the first and second stages of the experiment. From the previous test we know that the first stage and copper will cool down at the rate of 35 to $40 \mathrm{~K}$ per hour. Once the shield temperature reaches $150 \mathrm{~K}$, the first stage cool down rate may be a little faster, because there is less heat coming into the first stage due to the cooling of the second stage and helium tank. From the previous test we know that the tank will cool down at the rate of about $30 \mathrm{~K}$ per hour. The cool down of the helium tank from $290 \mathrm{~K}$ to about $5 \mathrm{~K}$ should take about 10 hours without adding liquid helium. If we allow the cooler to cool down the experiment, the helium fill will go faster without the introduction of air into the helium space.

4) Once the experiment is cold (with stage 1 at $50 \mathrm{~K}$ or below), fill the helium tank about eighty percent full. We have to allow for the expansion of liquid helium when its temperature is elevated above $4.2 \mathrm{~K}$. When the helium cools, it will contract. Is this going to cause a problem with superconductor inside the tank? I don't think it should, but I would like Bert's opinion on this.

5) Allow the whole experiment to cool down with no current flowing in any of the heater or through the leads. With not current and no extra heat into the second stage, I expect the second stage temperature to drop to between 3.1 and $3.3 \mathrm{~K}$. I expect the first stage temperature to be between 34 and $36 \mathrm{~K}$. Take data as the cooling of the experiment proceeds.

6) Once the temperatures in the experiment reach equilibrium, power the leads to their design current. Wait until the temperature in the experiment reaches equilibrium. Read the temperatures in the experiment. Measure the voltage drops across the copper leads and across the superconducting parts of the experiment. If the leads are optimum, the first stage temperatures should be between 38 and $40 \mathrm{~K}$. The second stage temperature should be between 3.1 and $3.3 \mathrm{~K}$.

7) Add $0.5 \mathrm{~W}$ of heat using the heater on the helium tank. Repeat steps 5 and 6. The first stage temperature shouldn't change very much, but the second stage temperature should increase into the range from 3.5 to $3.7 \mathrm{~K}$.

8) With the design current in the leads and $0.5 \mathrm{~W}$ of heat added to the helium tank, turn on the heater on the shield to put $30 \mathrm{~W}$ on the shield. Allow the experiment to come to equilibrium. Measure the temperatures and voltage drops in the experiment. The first stage temperatures should be between 51 and $53 \mathrm{~K}$. The second stage temperature should be between 3.8 and $4.0 \mathrm{~K}$.

9) With the design current in the leads and $0.5 \mathrm{~W}$ of heat added to the helium tank, increase the heat on the shield to $60 \mathrm{~W}$. Allow the experiment to come to equilibrium. Measure the temperatures and voltage drops in the experiment. The first stage temperatures should be between 70 and $75 \mathrm{~K}$. The second stage temperature should be between 4.0 and $4.2 \mathrm{~K}$.

10) Add $1.0 \mathrm{~W}$ of heat using the heater on the helium tank. Repeat steps 5 and 6. The first stage temperature should be about $35 \mathrm{~K}$, but the second stage temperature should increase into the range from 3.9 to $4.1 \mathrm{~K}$. 
11) With the design current in the leads and $1.0 \mathrm{~W}$ of heat added to the helium tank, turn on the heater on the shield to put $30 \mathrm{~W}$ on the shield. Allow the experiment to come to equilibrium. Measure the temperatures and voltage drops in the experiment. The first stage temperatures should be between 52 and $55 \mathrm{~K}$. The second stage temperature should be between 4.2 and $4.4 \mathrm{~K}$.

12) With the design current in the leads and $1.0 \mathrm{~W}$ of heat added to the helium tank, increase the heat on the shield to $60 \mathrm{~W}$. Allow the experiment to come to equilibrium. Measure the temperatures and voltage drops in the experiment. The first stage temperatures should be between 73 and $78 \mathrm{~K}$. The second stage temperature should be between 4.4 and $4.8 \mathrm{~K}$.

Steps 11 and 12 may result in helium tank operating pressure as high as 1.7 bar. In steps 5 and 6 the tank pressure could be as low 0.2 bars. The system should be able to operate over the pressure range from 0.2 to 1.7 bars.

At the very minimum, the experiment should be run with a pair of $60 \mathrm{~A}$ leads. The procedure for cooling down the experiment and operating the experiment should be as follows when a pair of 60-A leads connect from room temperature to the HTS leads:

1) Pump out the experiment and make sure that the vacuum is good enough to allow the experiment to be turned on. There should be no air leak into the experimental vacuum space.

2) Pressurize the experiment to a pressure of about $1.1 \mathrm{bar}$ (16.2 psia). Keep the experiment under this pressure during the cool down of the cooler and the helium tank.

3) Turn on the cooler and allow the cooler to cool down both the first and second stages of the experiment. From the previous test we know that the first stage and copper will cool down at the rate of 35 to $40 \mathrm{~K}$ per hour. Once the shield temperature reaches $150 \mathrm{~K}$, the first stage cool down rate may be a little faster, because there is less heat coming into the first stage due to the cooling of the second stage and helium tank. From the previous test we know that the tank will cool down at the rate of about $30 \mathrm{~K}$ per hour. The cool down of the helium tank from $290 \mathrm{~K}$ to about $5 \mathrm{~K}$ should take about 10 hours without adding liquid helium. If we allow the cooler to cool down the experiment, the helium fill will go faster without the introduction of air into the helium space.

4) Once the experiment is cold (with stage 1 at $50 \mathrm{~K}$ or below), fill the helium tank about eighty percent full. We have to allow for the expansion of liquid helium when its temperature is elevated above $4.2 \mathrm{~K}$. When the helium cools, it will contract. Is this going to cause a problem with superconductor inside the tank? I don't think it should, but I would like Bert's opinion on this.

5) Allow the whole experiment to cool down with no current flowing in any of the heater or through the leads. With not current and no extra heat into the second stage, I expect the second stage temperature to drop to between 3.1 and $3.3 \mathrm{~K}$. I expect the first stage temperature to be between 32 and $34 \mathrm{~K}$. Take data as the cooling of the experiment proceeds.

6) Once the temperatures in the experiment reach equilibrium, power the leads to their design current. Wait until the temperature in the experiment reaches equilibrium. Read the temperatures in the experiment. Measure the voltage 
drops across the copper leads and across the superconducting parts of the experiment. If the leads are optimum, the first stage temperatures should be between 34 and $36 \mathrm{~K}$. The second stage temperature should be between 3.1 and $3.3 \mathrm{~K}$.

7) Add $1.0 \mathrm{~W}$ of heat using the heater on the helium tank. Repeat steps 5 and 6. The first stage temperature should be about $35 \mathrm{~K}$, but the second stage temperature should increase into the range from 3.8 to $4.0 \mathrm{~K}$.

8) With the design current in the leads and $1.0 \mathrm{~W}$ of heat added to the helium tank, turn on the heater on the shield to put $30 \mathrm{~W}$ on the shield. Allow the experiment to come to equilibrium. Measure the temperatures and voltage drops in the experiment. The first stage temperatures should be between 49 and $53 \mathrm{~K}$. The second stage temperature should be between 4.1 and $4.3 \mathrm{~K}$.

Steps 7 and 8 may result in helium tank operating pressure as high as 1.1 bar. In steps 5 and 6 the tank pressure could be as low 0.2 bars. The system should be able to operate over the pressure range from 0.2 to 1.7 bars.

If one operates the experiment with the other two pairs of 300-A leads, the procedure for cooling down the experiment and operating the experiment should be as follows:

1) Pump out the experiment and make sure that the vacuum is good enough to allow the experiment to be turned on. There should be no air leak into the experimental vacuum space.

2) Pressurize the experiment to a pressure of $\sim 1.1$ bar (16.2 psia). Keep the experiment under this pressure during the cool down of the cooler and the helium tank.

3) Turn on the cooler and allow the cooler to cool down both the first and second stages of the experiment. From the previous test we know that the first stage and copper will cool down at the rate of 35 to $40 \mathrm{~K}$ per hour. Once the shield temperature reaches $150 \mathrm{~K}$, the first stage cool down rate may be a little faster, because there is less heat coming into the first stage due to the cooling of the second stage and helium tank. From the previous test we know that the tank will cool down at the rate of about $30 \mathrm{~K}$ per hour. The cool down of the helium tank from $290 \mathrm{~K}$ to about $5 \mathrm{~K}$ should take about 10 hours without adding liquid helium. If we allow the cooler to cool down the experiment, the helium fill will go faster without the introduction of air into the helium space.

4) Once the experiment is cold (with stage 1 at $50 \mathrm{~K}$ or below), fill the helium tank about eighty percent full. We have to allow for the expansion of liquid helium when its temperature is elevated above $4.2 \mathrm{~K}$. When the helium cools, it will contract. Is this going to cause a problem with superconductor inside the tank? I don't think it should, but I would like Bert's opinion on this.

5) Allow the whole experiment to cool down with no current flowing in any of the heater or through the leads. With not current and no extra heat into the second stage, I expect the second stage temperature to drop to between 3.1 and $3.3 \mathrm{~K}$. I expect the first stage temperature to be between 34 and $36 \mathrm{~K}$. Take data as the cooling of the experiment proceeds.

6) Once the temperatures in the experiment reach equilibrium, power the leads to their design current. Wait until the temperature in the experiment reaches equilibrium. Read the temperatures in the experiment. Measure the voltage 
drops across the copper leads and across the superconducting parts of the experiment. If the leads are optimum, the first stage temperatures should be between 38 and $40 \mathrm{~K}$. The second stage temperature should be between 3.1 and $3.3 \mathrm{~K}$.

7) Add $1.0 \mathrm{~W}$ of heat using the heater on the helium tank. Repeat steps 5 and 6. The first stage temperature should be about $35 \mathrm{~K}$, but the second stage temperature should increase into the range from 3.9 to $4.2 \mathrm{~K}$.

Steps 7 may result in helium tank operating pressure as high as 1.0 bar. In steps 5 and 6 the tank pressure could be as low 0.2 bars. The system should be able to operate over the pressure range from 0.2 to 1.7 bars.

\section{Test Procedure for Leads and the Cooler}

\section{What we want to measure:}

T1 Temperature of the helium tank

T2 Temperature of the cooler $2^{\text {nd }}$ stage

T5 Temperature of the Cooler $1^{\text {st }}$ Stage

T6 Temperature of the copper block connecting to the lead intercepts

T7 Temperature of the copper ring that connect to the cooler $1^{\text {st }}$ stage

T8 Temperature of the top of HTS lead number 1

T9 Temperature of the top of HTS lead number 2

T10 Temperature of the top of copper lead number 1

T11 Temperature of the top of copper lead number 2

$\mathrm{P} \quad$ The pressure in the helium tank when the system is re-condensing

V1-V3 Voltage drop across copper lead number 1

V3-V5 Voltage drop across HTS lead number 1

V5-V7 Voltage drop across $4 \mathrm{~K}$ feed through number 1

V7-V9 Voltage drop across the $\mathrm{S} / \mathrm{C}$ splice number 1

V2-V4 Voltage drop across copper lead number 2

V4-V6 Voltage drop across HTS lead number 2

V6-V8 Voltage drop across $4 \mathrm{~K}$ feed through number 2

V8-V10 Voltage drop across the S/C splice number 2

V9-V10 Voltage drop across the superconductor in the helium tank

Temperatures $\mathrm{T} 1$ and $\mathrm{T} 2$ are measured with silicon diodes. Temperatures $\mathrm{T} 5$ through T9 are measured with platinum resistance sensors. Temperature T10 and T11 are measured with a device that measure temperature by radiation. $P$ is measured with a compound pressure gauge that measure pressures above and below 1 atmosphere absolute. The voltage drops are measured while the current is flowing using a microvolt meter. 
Measurement Matrix for the Test

\begin{tabular}{|c|c|c|c|c|c|}
\hline Case & $\begin{array}{c}\text { Lead } \\
\text { \# }\end{array}$ & $\begin{array}{c}\text { Heater 1 } \\
\text { (W) }\end{array}$ & $\begin{array}{c}\text { Heater 2 } \\
\text { (W) }\end{array}$ & $\begin{array}{c}\text { Current } \\
\text { (A) }\end{array}$ & Remarks \\
\hline $\mathbf{1}$ & 1 & 0 & 0 & 0 & \\
\hline $\mathbf{2}$ & 1 & 0 & 0 & 275 & \\
\hline $\mathbf{3}$ & 1 & 30 & 0 & 275 & \\
\hline $\mathbf{4}$ & 1 & 0 & 0 & 275 & Before over night (like 2) \\
\hline $\mathbf{5}$ & 1 & 0 & 0 & 275 & After over night (like 2) \\
\hline $\mathbf{6}$ & 1 & 0 & 0.5 & 275 & \\
\hline $\mathbf{7}$ & 1 & 30 & 0.5 & 275 & \\
\hline $\mathbf{8}$ & 1 & 0 & 0.5 & 0 & \\
\hline $\mathbf{9}$ & 2 & 0 & 0 & 0 & \\
\hline $\mathbf{1 0}$ & 2 & 0 & 0 & 60 & \\
\hline $\mathbf{1 1}$ & 2 & 30 & 0 & 60 & \\
\hline $\mathbf{1 2}$ & 2 & 60 & 0 & 60 & Is this case stable? \\
\hline $\mathbf{1 3}$ & 3 & 0 & 0 & 0 & (like case 1) \\
\hline $\mathbf{1 4}$ & 3 & 0 & 0 & 275 & (like case 2) \\
\hline $\mathbf{1 5}$ & 3 & 60 & 0 & 275 & Is this stable? \\
\hline $\mathbf{1 6}$ & 3 & 60 & 0.5 & 275 & (like cases 1 and 13) \\
\hline $\mathbf{1 7}$ & 4 & 0 & 0 & 0 & (like case 8) \\
\hline $\mathbf{1 8}$ & 4 & 0 & 0.5 & 0 & \\
\hline $\mathbf{1 9}$ & 4 & 0 & 0.5 & 275 & \\
\hline $\mathbf{2 0}$ & 4 & 0 & 1.0 & 275 & \\
\hline $\mathbf{2 1}$ & 4 & 30 & 1.0 & 275 & Is this case stable? \\
\hline $\mathbf{2 2}$ & 4 & 60 & 1.0 & 275 & \\
\hline $\mathbf{2 3}$ & 4 & 0 & 0.5 & 275 & \\
\hline $\mathbf{2 4}$ & 4 & 30 & 0.5 & 275 & \\
\hline $\mathbf{2 5}$ & 4 & 60 & 0.5 & 275 & \\
\hline $\mathbf{2 6}$ & 4 & 80 & 0.5 & 275 & Take system to limit! \\
\hline & & & & & \\
\hline
\end{tabular}




\section{DISCLAIMER}

This document was prepared as an account of work sponsored by the United States Government. While this document is believed to contain correct information, neither the United States Government nor any agency thereof, nor The Regents of the University of California, nor any of their employees, makes any warranty, express or implied, or assumes any legal responsibility for the accuracy, completeness, or usefulness of any information, apparatus, product, or process disclosed, or represents that its use would not infringe privately owned rights. Reference herein to any specific commercial product, process, or service by its trade name, trademark, manufacturer, or otherwise, does not necessarily constitute or imply its endorsement, recommendation, or favoring by the United States Government or any agency thereof, or The Regents of the University of California. The views and opinions of authors expressed herein do not necessarily state or reflect those of the United States Government or any agency thereof, or The Regents of the University of California. 